\title{
ASPECTOS BIOLÓGICOS E TÉCNICA DE CRIAÇÃO DE Metallactus sp. (COLEOPTERA: CHRYSOMELIDAE: CRYPTOCEPHALINAE) EM Eucalyptus urophylla S.T. BLAKE
}

\section{MOISÉS FRANCISCO PERECIN}

Dissertação apresentada à Escola Superior de Agricultura "Luiz de Queiroz", Universidade de São Paulo, para obtenção do título de Mestre em Ciências, área de concentração: Entomologia.

P I R A C I C A B A

Estado de São Paulo - Brasil Junho - 2003 


\section{ASPECTOS BIOLÓGICOS E TÉCNICA DE CRIAÇÃO DE Metallactus sp. (COLEOPTERA: CHRYSOMELIDAE: CRYPTOCEPHALINAE) \\ EM Eucalyptus urophylla S.T. BLAKE}

\section{MOISÉS FRANCISCO PERECIN}

Biólogo

Orientador: Prof. Dr. EVONEO BERTI FILHO

Dissertação apresentada à Escola Superior de Agricultura "Luiz de Queiroz", Universidade de São Paulo, para obtenção do título de Mestre em Ciências, área de concentração: Entomologia.

P I R A C I C A B A

Estado de São Paulo - Brasil

Junho - 2003 
Dados Internacionais de Catalogação na Publicação (CIP) DIVISÃO DE BIBLIOTECA E DOCUMENTAÇÃO - ESALQ/USP

\author{
Perecin, Moisés Francisco \\ Aspectos biológicos e técnicas de criação de Metallactus sp. (Coleoptera: \\ Chrysomelidae: Cryptocephalinae) em Eucalyptus urophylla S. T. Blake / Moisés \\ Francisco Perecin. - - Piracicaba, 2003. \\ 66 p. : il. \\ Dissertação (mestrado) - - Escola Superior de Agricultura Luiz de Queiroz, \\ 2003. \\ Bibliografia.
}

1. Besouros 2. Biologia 3. Coleoptera 4. Eucalipto 5. Insetos (Criação) 6. Pragas de plantas I. Título

CDD 632.76

"Permitida a cópia total ou parcial deste documento, desde que citada a fonte - O autor" 
Ao meu pai Elio, meu avô Antonio e aos mestres Hugo Liva e Antonio do Amaral, ofereço

A minha esposa Sílvia e meu filho Guilherme, dedico 


\section{AGRADECIMENTOS}

Ao Dr. Evoneo Berti Filho, Professor Titular do Departamento de Entomologia, Fitopatologia e Zoologia Agrícola da Escola Superior de Agricultura "Luiz de Queiroz" (ESALQ), da Universidade de São Paulo (USP), pelo incentivo, orientação, confiança, amizade e apoio na condução desta pesquisa;

Ao professor Dr. Sinval Silveira Neto, Professor Titular do Departamento de Entomologia, Fitopatologia e Zoologia Agrícola da Escola Superior de Agricultura "Luiz de Queiroz" (ESALQ), da Universidade de São Paulo (USP), pela colaboração e apoio no desenvolvimento desta pesquisa;

Aos professores do Curso de Pós-Graduação em Entomologia da ESALQ/USP, pelos ensinamentos transmitidos durante o curso;

À $\operatorname{Dr}^{\mathrm{a}}$ Elizabeth Basso Bernardi, pela amizade, paciência e colaboração na condução desta pesquisa;

Ao Dr. Matthias Schöller, do Biologische Beratung Berlin, Alemanha, pela atenção e inestimável colaboração com a descrição da espécie;

À Bióloga Patrícia Milano pela amizade e confecção das ilustrações;

Ao Biólogo Heraldo Negri de Oliveira pela amizade e pelo valioso trabalho fotográfico; 
À RIPASA Celulose e Papel S/A, pela permissão do uso da área para os trabalhos de campo e, em especial, aos funcionários, Richard, Alemão e Eleno, pela atenção e colaboração no trabalho de campo;

Ao Dr. Maurício Bento pelas sugestões na revisão do trabalho;

Ao Doutorando Dori Nava pela amizade e pelas sugestões que muito auxiliaram na condução da pesquisa;

Ao professor Leonardo Gonçalves, do Departamento de Ciências Florestais, da ESALQ/USP, pela colaboração e disponibilidade no fornecimento das plântulas de Eucalyptus sp. e dos funcionários Sr. Chico, Amarildo e Luciana pela colaboração no desenvolvimento deste trabalho;

Aos colegas de curso pelo companheirismo: Marcelo Poletti, Ricardo, Diogo, Roberto, Keiko, Ana Lia, Rosa, Cássia, Jerson, Geni, Daniela, Antonio, Alex e Luciane;

As bibliotecárias Eliana M. G. Sabino e Sílvia Zinsly pela revisão na bibliografia;

Aos funcionários Ana, Neide, João Cerignoni, João, Vítor, Tutu, Edilene, Carlinhos e Dino pela amizade e colaboração;

A todos que direta ou indiretamente contribuíram para a execução deste trabalho. 


\section{SUMÁRIO}

Página

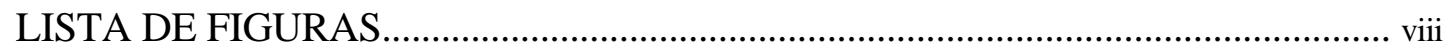

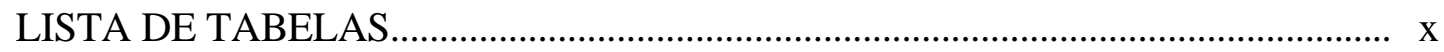

RESUMO

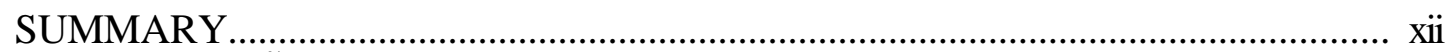

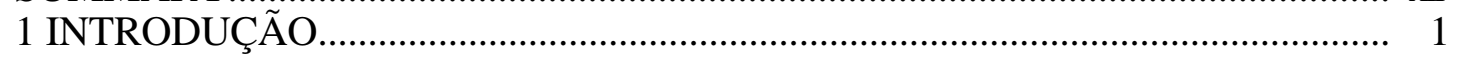

2 REVISÃO DE LITERATURA........................................................................... 3

2.1 Coleópteros em plantios de Eucalyptus spp. no Brasil............................................ 3

2.2 Características gerais de Cryptocephalinae........................................................... 4

2.3 Ciclo de vida............................................................................. 5

2.4 Hábitos de Cryptocephalinae .......................................................................... 10

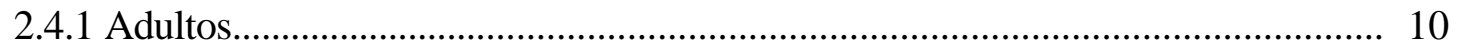

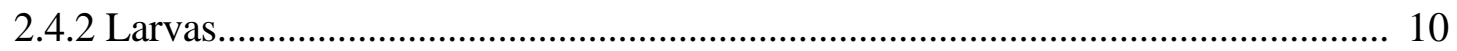

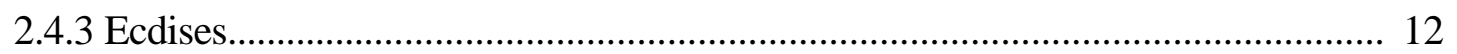

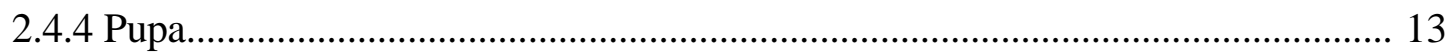

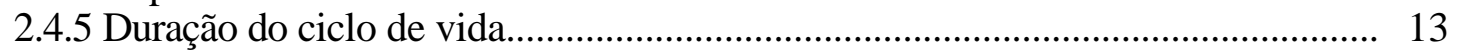

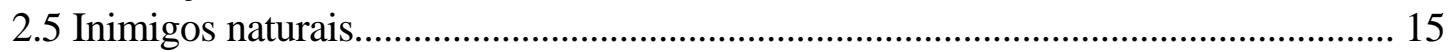

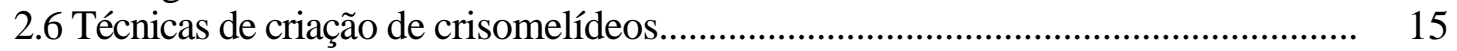

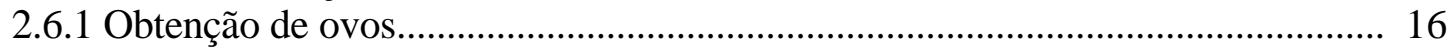

2.6.2 Desenvolvimento larval e pupal......................................................................... 17

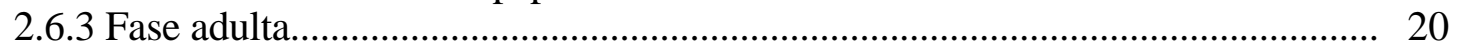

2.7 Condições controladas em laboratório................................................................ 22

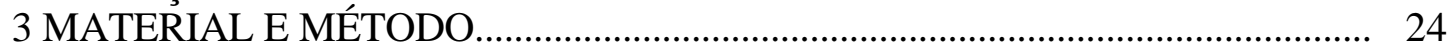

3.1 Avaliação dos parâmetros biológicos................................................................... 24

3.2 Técnica de criação de Metallactus sp. ................................................................... 24

3.2.1 Coleta de adultos no campo e obtenção de ovos.................................................. 25

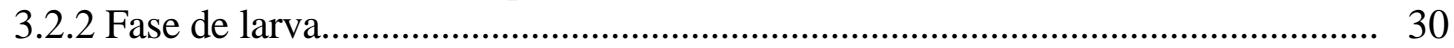

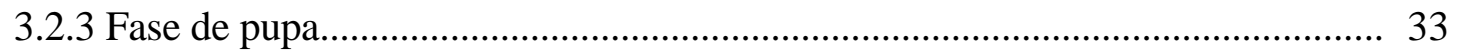

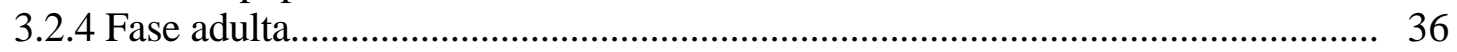

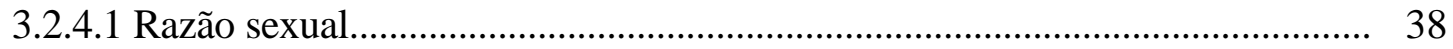

3.2.4.2 Tabela de vida de fertilidade........................................................................ $\quad 38$

4 RESULTADOS E DISCUSSÃO_.................................................................... 39

4.1 Identificação da espécie............................................................................... $\quad 39$

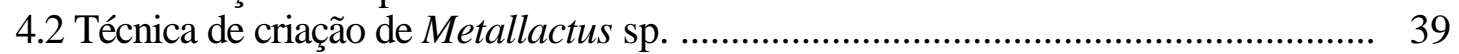

4.3 Biologia de Metallactus sp. .......................................................................... 42 


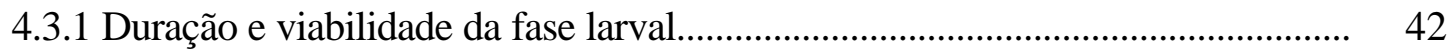

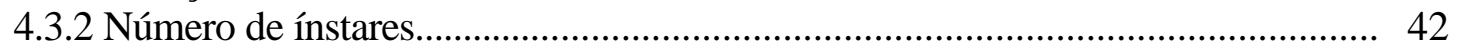

4.3.3 Duração e viabilidade dos períodos de pré-pupa e pupa....................................... 44

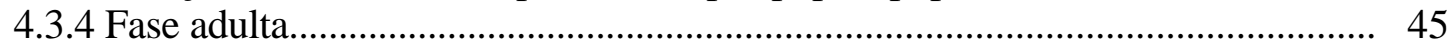

4.3.4.1 Períodos de pré-oviposição e oviposição............................................................ 45

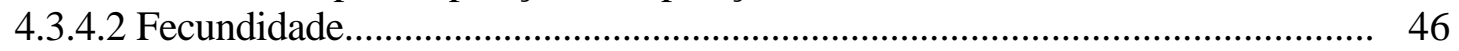

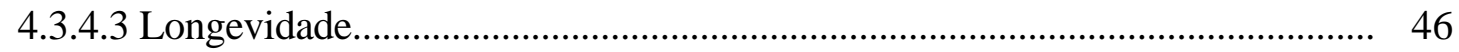

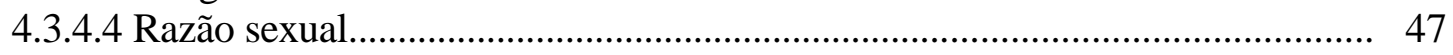

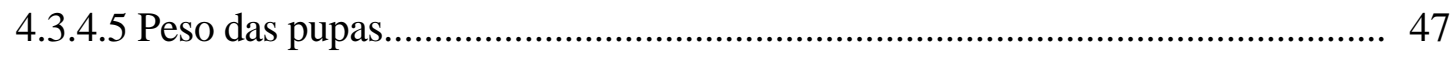

4.3.4.6 Tabela de vida de fertilidade............................................................................. 48

4.3.4.7 Duração e viabilidade do ciclo total (ovo-adulto)............................................ 50

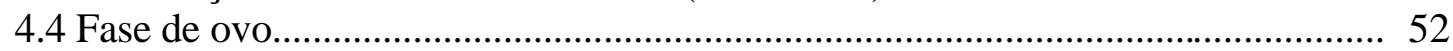

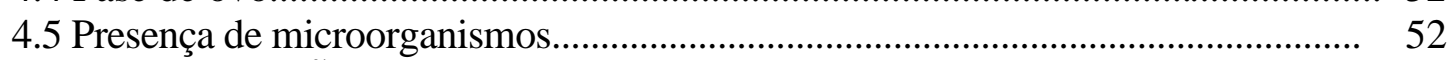

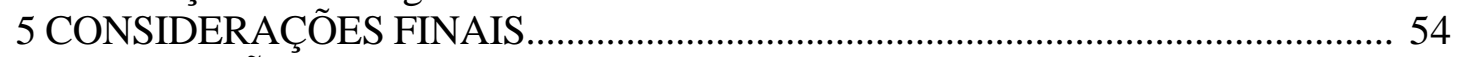

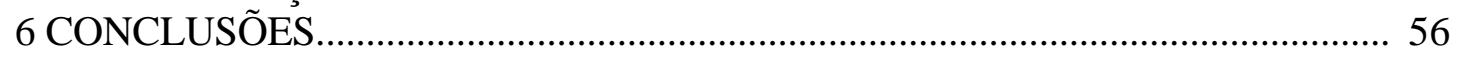

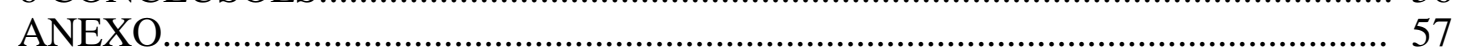

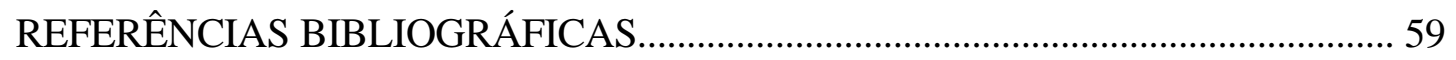




\section{LISTA DE FIGURAS}

Página

1 Danos causados aos ponteiros de Eucalyptus urophylla, no campo, por adultos de Metallactus sp.

2 Gaiola cilíndrica de poliestireno transparente(maior) para manutenção e transporte dos adultos de Metallactus sp

3 Adulto de Metallactus sp. sobre folha de Eucalyptus urophylla.

4 Placa de poliestireno transparente contendo "egg-case", ovos e "pellets" de Metallactus sp.

5 "Egg-case" de Metallactus sp. aberta expondo o ovo (esquerda) e ovo sem a "egg-case"

6 Larva de último ínstar de Metallactus sp. com cabeça e pernas projetadas fora da escatoteca, para locomoção

7 Larva de último ínstar de Metallactus sp. fora da escatoteca. À direita, escatoteca em vista lateral. 
8 Escatotecas de Metallactus sp. com tampa provisória (esquerda) e com tampa definitiva

9 Escatotecas de Metallactus sp. contendo a larva na posição normal (esquerda) e em posição invertida, para pupação.

10 Pupas de Metallactus sp. em vista lateral (esquerda) e ventral

11 Dimorfismo sexual de adultos de Metallactus sp. mostrando as diferenças nos últimos segmentos abdominais (vista ventral).

12 Técnica de criação de Metallactus sp. em Eucalyptus urophylla

13 Curva de distribuição de frequiências de larguras de cápsulas cefálicas de larvas de Metallactus sp., mantidas em Eucalyptus urophylla. As setas indicam os ínstares. Temp.: $25 \pm 1^{\circ} \mathrm{C}$; UR: $90 \pm 5 \%$ e fotofase: 14 horas

14 Emergência de Metallactus sp. através da retirada de uma tampa do lado oposto à abertura da escatoteca

15 Ciclo total (ovo-adulto) de Metallactus sp. em Eucalyptus urophylla

16 "Egg-case" de Metallactus sp. com a presença de microorganismos. 


\section{LISTA DE TABELAS}

Página

1 Largura média da cápsula cefálica, constante de Dyar e coeficiente de correlação de Metallactus sp., mantido em plântulas de Eucalyptus urophylla. Temp.: $25 \pm 1^{\circ} \mathrm{C}$; UR: $90 \pm 5 \%$ e fotofase: 14 horas..

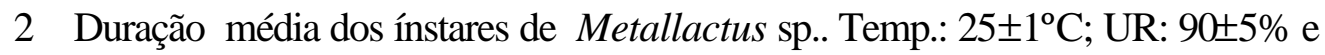
fotofase: 14 horas.

3 Fecundidade e longevidade de fêmeas de Metallactus sp. $(\mathrm{N}=19)$.

4 Tabela de vida de fertilidade para Metallactus sp., criado em plântulas de Eucalyptus urophylla. Temp.: $25 \pm 1^{\circ} \mathrm{C}$; UR: $90 \pm 5 \%$ e fotofase: 14 horas............ 


\title{
ASPECTOS BIOLÓGICOS E TÉCNICA DE CRIAÇÃO DE Metallactus sp. (COLEOPTERA: CHRYSOMELIDAE: CRYPTOCEPHALINAE) EM Eucalyptus urophylla S.T. BLAKE
}

\author{
Autor: MOISÉS FRANCISCO PERECIN \\ Orientador: Prof. Dr. EVONEO BERTI FILHO
}

\section{RESUMO}

Esta pesquisa teve por objetivos avaliar os aspectos biológicos de Metallactus sp. em Eucalyptus urophylla e desenvolver uma técnica de criação do inseto em laboratório. As condições ambientais foram: temperatura $25 \pm 1^{\circ} \mathrm{C}$, umidade relativa de $90 \pm 5 \%$ e fotofase de 14 horas. Os parâmetros biológicos avaliados foram: duração, viabilidade da fase larval e número de ínstares larvais; duração, viabilidade da fase pupal e peso da escatoteca; longevidade de machos e fêmeas, razão sexual, dimorfismo sexual, período de pré-oviposição, período de oviposição, número de ovos por fêmea; período de incubação e viabilidade dos ovos; duração e viabilidade do ciclo (ovo-adulto) e tabela de vida de fertilidade. 


\title{
Metallactus sp. (COLEOPTERA: CHRYSOMELIDAE: CRYPTOCEPHALINAE): BIOLOGICAL ASPECTS AND REARING TECHNIQUE ON Eucalyptus urophylla S.T. BLAKE
}

\author{
Author: MOISÉS FRANCISCO PERECIN
} Adviser: Dr. EVONEO BERTI FILHO

\section{SUMMARY}

This paper deals with the biological aspects of Metallactus sp. on Eucalyptus urophylla and the development of a technique to rear this insect in laboratory $\left(25 \pm 1^{\circ} \mathrm{C}\right.$; 90 $\pm 5 \% \mathrm{RH} ;$ 14-hour photophase). The following parameters were evaluated: duration, viability and number of instars of the larval stage; duration and viability of the pupal stage; case weight; longevity of male and female adults; sex ratio; sexual dimorphism; preoviposition period; oviposition period; number of eggs per female; egg period and egg viability; duration and viability of the life cycle (egg-adult period); and fertility life table. 


\section{INTRODUÇÃO}

As florestas plantadas no Brasil representam aproximadamente $1 \%$ da cobertura florestal, com cerca de 5 milhões de hectares, sendo que apenas nos estados de São Paulo e Minas Gerais, há mais de $70 \%$ de todo eucalipto plantado em território nacional (SBS, 2002).

Estas florestas têm um papel fundamental para o setor florestal brasileiro e, conseqüentemente, para a economia nacional, servindo de matéria-prima para os setores de celulose e papel, chapas, aglomerados, laminados e serraria, dentre outros, colaborando para a diminuição da pressão na utilização das florestas naturais.

Espécies do gênero Eucalyptus são cultivadas em muitas regiões do mundo devido a capacidade de adaptarem-se aos mais variados tipos de hábitats (Zanuncio et al., 1993). No entanto, monoculturas de eucalipto podem favorecer a ocorrência de pragas devido à grande oferta de alimento para insetos e ao desequilíbrio na estrutura da vegetação natural, o que tem tornado necessário o desenvolvimento de técnicas apropriadas para reduzir os danos causados (Schowalter et al., 1986).

No Brasil os lepidópteros desfolhadores de eucaliptos são estudados com maior intensidade, por serem responsáveis, juntamente com as formigas cortadeiras, pelos maiores danos causados ao setor florestal (Berti Filho, 1974; Santos et al., 1979; 
Zanuncio \& Lima, 1975; Zanuncio et al., 1990). Os coleópteros constituem o terceiro grupo de insetos mais importantes para a silvicultura brasileira, principalmente as espécies das famílias Scolytidae, Buprestidae, Platypodidae, Scarabaeidae, Cerambycidae Chrysomelidae e Curculionidae, (Berti Filho \& Krugner, 1986; PedrosaMacedo, 1993; Zanuncio et al., 1993), sendo que as últimas três famílias estão entre as mais importantes nas regiões onde o eucalipto é nativo (Ohmart \& Edwards, 1991).

O besouro Metallactus sp. (Chrysomelidae: Cryptocephalinae) teve seu primeiro registro, em março de 2000, na região de Boa Esperança do Sul, na Fazenda Flecha Azul, da Ripasa S/A Papel e Celulose, no Estado de São Paulo, causando danos às brotações e ponteiros, em plantios novos de Eucalyptus urophylla. Em janeiro de 2001, aproximadamente $20 \%$ das mudas e rebrotas de E. urophylla, de um total de 40.000 mudas foram atacadas e danificadas, sendo necessário substituí-las.

Este trabalho eve como objetivo estudar, o ciclo biológico de Metallactus sp., em plântulas de E. urophylla e desenvolver uma técnica de criação em laboratório. 


\section{REVISÃO DE LITERATURA}

\subsection{Coleópteros desfolhadores de Eucalyptus spp. no Brasil}

Há poucas referências atualizadas sobre besouros desfolhadores em plantios de eucaliptos. Andrade (1928) elaborou uma lista dos insetos observados em essências florestais, em sua maioria coleobrocas. Sobre esse grupo de insetos foi desenvolvido por Mariconi (1956) um trabalho com informações gerais de algumas espécies das famílias Chrysomelidae e Scarabaeidae. Andrade (1961) e Pinheiro (1962) também forneceram uma lista dos insetos que ocorrem na cultura do eucalipto.

Existe uma significativa referência bibliográfica (Silva et al., 1968) sobre as espécies de besouros desfollhadores brasileiros, inclusive Metallactus quindecimguttatus atacando Eucalyptus sp. e Psidium guajava, mas ela foi compilada só até 1963, portanto, cerca de 40 anos de pesquisas sobre besouros desfolhadores no Brasil estão, ainda, para serem inventariados (Anjos, 2002).

A família Chrysomelidae tem sido reconhecida como prejudicial ao eucalipto, no Brasil, por vários autores (Berti Filho \& Krugner, 1986; Pedrosa-Macedo, 1993; Zanuncio et al., 1993). 
Anjos (1992) estudou o ciclo de vida da principal espécie de besouro desfolhador que apresenta importância para o setor florestal brasileiro, Costalimaita ferruginea, comumente denominado besouro amarelo do eucalipto.

O fato de os besouros desfolhadores serem polífagos e algumas espécies terem causado danos em vários locais, demonstra que eles têm potencial para se tornarem amplamente distribuídos e causarem maiores danos com a expansão da eucaliptocultura (Mezzomo et al., 1998).

\subsection{Características gerais de Cryptocephalinae}

Há somente uma referência com o gênero Metallactus no Brasil (McFayden, 1987), tornando-se necessário a utilização do trabalho de Erber (1988), de abrangência mundial, como base para essa revisão.

A família Chrysomelidae possui dezenove subfamílias, divididas em cinco seções, dentre elas, a seção Camptosomata, que engloba as subfamílias Clytrinae, Cryptocephalinae, Chlamisinae e Lamprosomatinae, apresentando uma peculiaridade na reprodução e desenvolvimento: as fêmeas cobrem os ovos com material fecal, formando uma camada de proteção para os ovos(“egg-case”) que, após a eclosão das larvas, será utilizada como um "estojo" de proteção (escatoteca), pelas larvas. A escatoteca aumenta à medida que as larvas crescem e por esta razão, Camptosomata são denominados, em inglês, de "casebearers" (Erber, 1988). 
Os coleópteros da subfamília Cryptocephalinae são de tamanho reduzido (aproximadamente de 1,5 a 6,0 mm de comprimento). O formato do corpo, geralmente, é cilíndrico, com os extremos arredondados, curtos e robustos. Em vista dorsal, a cabeça está completa ou quase completamente coberta pelo pronoto. A superfície do corpo, no geral, é brilhante e muitos apresentam cores vivas, com manchas (White,1975; Reid, 1999), ou ainda, podem apresentar padrão metálico (Erber, 1988).

Geralmente as larvas são protegidas pelas escatotecas e vivem no "litter", enquanto que os adultos são de vida livre e encontrados sobre as folhas da planta hospedeira (Erber, 1988; Schöller, 1999).

A maioria das espécies do grupo Camptosomata é termófila, fato mostrado pela abundância numérica nos trópicos, o que também se aplica dentro das zonas temperadas, porém, raramente aparecem em grande número (Erber, 1988).

Muitas espécies vivem de forma críptica ou deixam-se cair ao serem perturbadas. Por causa desse tipo de comportamento, pouco é conhecido sobre o ciclo de vida e seus hábitos, principalmente relacionados à alimentação, à reprodução e ao desenvolvimento (Erber, 1988).

\subsection{Ciclo de vida}

Por causa dos hábitos crípticos, o conhecimento do ciclo de vida da maioria das espécies é fragmentado ou desconhecido, sendo que Cryptocephalus pini, 
Labidostomis cyanicornis e Clytra quadripunctata (Erber) ${ }^{1}$, citado por Erber (1988), foram as únicas espécies estudadas mais detalhadamente e, por apresentarem semelhanças no desenvolvimento, forneceram a maioria dos dados básicos para que fosse possível descrever o ciclo de vida do grupo ( Erber, 1988).

Durante o acasalamento, o macho "monta" a fêmea colocando suas pernas sob os élitros dela ou, ainda, prende-a com o seu primeiro par de pernas, na junção do tórax com o élitro, mantendo as outras pernas em cima do corpo da fêmea. A cópula pode durar de horas a dias e uma fêmea acasala, provavelmente, com vários machos, um após o outro (Erber, 1988)

A oviposição inicia-se logo após o acasalamento, porém a fêmea precisa ter se alimentado, pois os ovos são inteiramente envolvidos por pequenas porções de excrementos, após a postura, formando uma camada de proteção (“egg-case”). As porções saem do ânus e apresentam uma forma específica que diferem dos "pellets" de excremento. Para envolver os ovos com esse material, as fêmeas apresentam um aparato quitinoso no reto, que consiste em vários escleritos organizados em um círculo na seção mediana do reto, com espessas camadas de músculo. O aparato é utilizado pela fêmea para comprimir uma de porção de excremento em uma superfície plana. Ao mesmo tempo, um fluido é secretado pelas glândulas retais que se misturam ao excremento, dando flexibilidade e estabilidade ao conjunto (Erber, 1988).

\footnotetext{
${ }^{1}$ Erber, D. Bau, Funktion und Bildung der Kotpresse mitteleuropaischer Clytrinen und Cryptocephalinen (Coleoptera, Chrysomelidae). Z. Morph. Tiere, v.62, p.245 -306, 1968.
} 
Durante a oviposição, a fêmea pousa em uma folha ou ramo da planta hospedeira e prende-se através dos dois primeiros pares de pernas, com a parte posterior do corpo dirigida para cima. O terceiro par de pernas é utilizado para, assim que o ovo sair da vulva, segurá-lo e pressioná-lo em uma depressão no sétimo esternito abdominal, em uma posição longitudinal, com a posição anterior dirigida para a cabeça da fêmea. Uma pequena porção do excremento sai do ânus e é aplicada àsuperfície total do ovo, através dos movimentos dos seis escleritos que cercam o ânus, juntamente com o pigidium. Os tarsos giram o ovo, aos poucos, ao redor do eixo longitudinal e as porções de excrementos são adicionadas umas as outras, até a formação de um anel que envolve uma faixa da superfície do ovo. Os tarsos movem, então, o ovo um pouco ao longo de seu eixo lateral, para trás, de forma que a próxima camada possa ser formada e adicionada à anterior. Por último, uma pequena camada de excremento é adicionada à porção polar do ovo. Depois de completar as camadas e envolver o ovo por completo, a fêmea pode simplesmente deixar o ovo ("egg-case") cair ao solo ou, dependendo da espécie, prendê-lo ao substrato com uma substância adesiva produzida pelas glândulas anais (Erber, 1988).

As "egg-case" apresentam uma grande variedade de formas, devido aos diferentes tipos de aparatos retais das fêmeas e, consequentemente, de como o material é depositado na superfície do ovo. Cryptocephalinae apresenta o material fecal depositado em fileiras espiraladas e organizadas, formando uma cobertura semelhante a um telhado com pontas proeminentes; com as placas convexas e justapostas ou, ainda, apresentando uma quilha longitudinal (Erber, 1988). 
Após um período que pode variar de doze a vinte e oito dias, dependendo da espécie, a larva eclode através do rompimento do polo frontal do ovo, onde faz um sulco circular na parede da camada de proteção, formando uma tampa que é empurrada pela larva ao sair do ovo. A tampa é desprezada pela larva, mas a camada de proteção que cobria o ovo, depois de aberta, é carregada pela larva, formando uma estrutura de proteção (Erber, 1988).

A estrutura de proteção (escatoteca) é vital para larva, pois uma vez perdida, danificada ou retirada, comprometerá sua sobrevivência, e poderá levá-la à morte por dessecação ou por dano ao abdômen (Erber, 1988; Scholler, 1999).

As larvas permanecem dentro da escatoteca com o abdômen curvado, o que assegura que elas possam remover as fezes do ânus, com as mandíbulas, e adicionálas à escatoteca, a medida que necessitam aumentar o tamanho dessa estrutura. Quando ameaçada, retrai-se para o interior da escatoteca e a cápsula cefálica, fortemente esclerotizada, forma um lacre de proteção, fechando a escatoteca. Para a locomoção ou alimentação, a larva expulsa sua cabeça e os três pares de pernas para o exterior da escatoteca, sendo que a escatoteca é presa pelo abdomen encurvado. Quando se move, a larva jovem mantém a escatoteca para cima e num plano inclinado, em relação ao solo. Larvas mais velhas arrastam-na, paralelamente ao solo (Erber, 1988).

As escatotecas são ampliadas com o crescimento da larva, por adição de pequenas camadas do seu próprio material fecal, acrescido de uma secreção adesiva. Com as mandíbulas levam as fezes do ânus e aplicam-nas na extremidade da abertura da escatoteca. Quando a larva precisa alargar a escatoteca, o que acontece, provavelmente, antes de cada muda, ela abre uma linha ventral, ao longo do comprimento da escatoteca 
e deposita, nesse local, uma pequena porção de material fecal, aumentando a área da estrutura. Antes de cada muda a larva lacra a escatoteca com uma tampa provisória, construída com excrementos e prende a escatoteca, pela abertura, contra um substrato, como madeira ou rocha, ou qualquer outra superfície sólida (Erber, 1988).

Também antes da pupação a larva lacra a escatoteca, porém de forma definitiva e com o material utilizado apresentando cor e textura diferentes da tampa provisória da muda. Dentro da escatoteca, hermeticamente fechada, a larva inverte sua posição, de forma que sua cabeça passa a ocupar a posição oposta à abertura da escatoteca, por onde o adulto emergirá após fazer uma abertura circular em toda a extensão da superfície da escatoteca (LeSage, 1984; Erber, 1988).

Assim como as "egg-case", as escatotecas variam quanto a forma, sendo que a forma característica aparece somente com a larva madura e é influenciada, inicialmente, pela forma da "egg-case". Na maioria dos casos, o lado dorsal é mais convexo que o lado ventral. A forma característica da escatoteca de Cryptocephalinae é a de um saco, que pode ter a superfície granular ou reforçada por estruturas mais fortes (LeSage, 1984; Erber, 1988).

O material utilizado para a construção da "egg-case" e da escatoteca é, na maioria das espécies, constituído de fezes umedecidas com secreções produzidas por glândulas retais (Erber, 1988). 


\subsection{Hábitos de Cryptocephalinae}

\subsubsection{Adultos}

Os adultos são fitófagos, utilizando como alimento folhas verdes de espécies lenhosas e herbáceas, de uma grande variedade de espécies, embora algumas espécies já apresentem um início de especificidade hospedeira; de pétalas e pólen (Erber, 1988); flores ou frutos e, algumas vezes, de plantas de importância econômica (White, 1975) e, ainda, há espécies encontradas no interior do ninho de formigas do gênero Crematogaster spp. (Erber, 1988).

\subsubsection{Larvas}

O hábitat larval e o tipo de alimento diferem daqueles dos adultos. As larvas da maior parte das espécies vivem no solo, com apenas poucas espécies vivendo nas plantas, outras, ainda, são inquilinas em formigueiros, onde passam todo o período larval e o estágio de pupa. De modo geral, as larvas vivem dentro de uma estrutura de proteção (escatoteca) e são de vida livre, rastejam sobre o solo, procurando material vegetal seco e em decomposição (LeSage, 1984; White, 1975; Erber, 1988; Reid, 1999).

Não é conhecido se elas preferem partes específicas das plantas ou restos de uma grande variedade de plantas, em um estágio particular de decomposição; além de não haver informações suficientes para se afirmar se estas precisam alimentar-se de partes verdes da planta hospedeira, pelo menos antes da pupação. Em condições de 
laboratório, foi constatado que elas preferem as partes secas das plantas, às partes verdes (LeSage, 1984; Erber, 1988).

De acordo com Reid (1999) as larvas se alimentam de folhas em decomposição no "litter" e necessitam, para o seu desenvolvimento, da presença de folhas, fungos ou bactérias específicos, o que dificulta a sua criação em laboratório.

LeSage $(1985 ; 1986)$ mostrou que Pachybrachis peccans e P. bivittatus não podem escalar as plantas e, portanto, não se alimentam em folhas verdes, o que não acontece com as larvas de Cryptocephalus venustus e C. quadruceps que podem escalar as plantas, no terceiro ínstar. Massuti (1960), observou que as larvas de C. pini se alimentam de folhas secas, porém, antes da muda, elas se alimentam de folhas verdes.

Poucas são as espécies que se alimentam exclusivamente de plantas verdes. Reineck ${ }^{2}$, citado por Erber (1988), relatou que as larvas de C. janthinus se alimentam em folhas de Phragmites (Poaceae). LeSage (1984) observou larvas de Lexiphanes saponatus em Cassandra calyculata(Ericaceae).

\footnotetext{
${ }^{2}$ Reineck, G. Beitrag zur Lebensweise von Cryptocephalus janthinus Germ. Dtsch. Ent. Z, v.58, p.163, 1913
} 


\subsubsection{Ecdises}

Antes de cada muda e, em geral, durante o processo da ecdise, a larva fica por um período mais longo, dentro da escatoteca, fixando a abertura em algum substrato sólido. Na maioria dos casos a abertura é fechada hermeticamente com fezes. As larvas que vivem em material em decomposição e não encontram uma base sólida, recortam um orifício em uma folha e lacram-no, de tal modo que as fezes sobrepõem as extremidades do buraco, no lado oposto. Apesar das tampas provisórias fornecerem um indício do processo de muda, é difícil precisar o número porque para acompanhar o processo, a escatoteca deveria ser aberta, o que normalmente conduziria à morte da larva. Outro fator limitante é o fato da larva devorar a exúvia (Erber, 1988).

Diversos autores, citados por Erber (1988) observaram três ínstares, como Fiori $^{3}$ para Cryptocephalus frenatus, Medvedev ${ }^{4}$ para C. octomaculatus, Medvedev \& Zaitzev ${ }^{5}$ para Cryptocephalus sp. e Pachybrachis sp.; Masutti (1960) observou quatro ínstares para C. pini. LeSage $(1985 ; 1986)$ observou cinco ínstares para C. venustus.

\footnotetext{
${ }^{3}$ Fiori, G. Contributi alla connescenza morfologica ed etologica dei Colleotteri. V. Coptocephala kusteri Kraatz e Cryptocephalus frenatus Laich. Boll. Ist. Ent. Univ. Bologna., v.18, p.182-196, 1951.

${ }^{4}$ Medvedev, L. N. Systematics and Biology of the Larvae of the Subfamily Clytrinae (Coleoptera, Chrysomelidae). Zool. Zh., v.41, n.9, p.1334-1344, 1962.

${ }^{5}$ Medvedev, L. N.,Zaitzev, Y. M. The Larvae of Chrysomelid Beetles of Siberia and the Far East. Nauka, Moscow, 182p., 1978.
} 


\subsubsection{Pupa}

A larva madura fixa-se a uma base sólida e fecha, hermeticamente, a abertura da escatoteca. Entre as espécies que vivem no solo, isto ocorre principalmente em detritos vegetais, sob as rochas ou mesmo perfurando um pequeno orifício a poucos centímetros do solo. As larvas de espécies fitófagas, provavelmente, pupam próximo das plantas hospedeiras. As espécies mirmecófilas procuram um substrato sólido no interior dos ninhos das formigas (LeSage, 1984; Erber, 1988).

A duração do período pupal está entre 12 e 28 dias para os representantes da seção Camptosomata., considerando o tempo que as larvas permanecem imóveis (prépupa) e o tempo que de fato elas levam para transformar-se em pupa. $\mathrm{O}$ adulto permanece na escatoteca por 2 a 3 dias, antes de abrí-la e sair (Erber, 1988; LeSage, 1984).

Masutti (1960), observou um período de 28 dias para o desenvolvimento pupal de Cryptocephalus pini.

\subsubsection{Duração do ciclo de vida}

O período de desenvolvimento, de ovo à emergência do adulto, pode ser de aproximadamente um ano, como observado por LeSage (1986) para Cryptocephalus quadruplex e C. venustus (América do Norte) e por Masutti (1960), para C. pini, Medvedev ${ }^{4}$, citado por Erber (1988), relatou dois anos para C. octomaculatus. De acordo com Medvedev \& Zaitzev ${ }^{5}$, citados por Erber (1988), todos os Cryptocephalinae, 
inclusive Pachybrachis sp., precisam de dois anos para o desenvolvimento completo, na Sibéria.

Segundo Erber (1988), as larvas de algumas espécies podem desenvolverse rapidamente, de forma que estão prontas para pupar após um ano, entretanto, outras da mesma espécie, necessitam de dois anos para pupar e, algumas poucas, de três anos ou mais, fenômeno também observado para Pachybrachis sp. por LeSage (1985), ocorrendo ainda, larvas de algumas espécies podem interromper a alimentação por um longo período de tempo, mesmo quando há abundância de alimento.

Erber $^{6}$, citado por Erber (1988) relatou que os adultos de Cryptocephalus flavipes e $C$. cyanipes iniciam suas atividades, na América do Norte, em maio e junho, período em que as fêmeas colocam os ovos. As larvas que eclodem hibernam quando maduras e começam a pupar em abril ou maio do ano seguinte. Segundo White (1975) Metallactus sp. aff. nigrofasciatus também hiberna como larva madura.

\footnotetext{
${ }^{6}$ Erber, D. Beitrag zur Entwicklungsbiologie mitteleuropäischer Clytrinen und Cryptocephalinen (Coleoptera, Chrysomelidae). Zool. Jb. Syst., v.96, p.453-477, 1969.
} 


\subsection{Inimigos naturais}

Apesar das estruturas de proteção do ovo "egg-case" e da larva (escatoteca), Cryptocephalinae tem como inimigos naturais, principalmente Hymenoptera parasitóides de larvas (Braconidae, Ichneumonidae, Pteromalidae, Eulophidae, Eupelmidae) e como predador, Laphria gibbosa (Diptera: Asilidae), que ataca adultos de Cryptocephalus sericeus (Erber, 1988). McFadyen (1987) estudando a biologia de Metallactus patagonicus em folhas de Braccharis articulata, verificou a presença de parasitóides de larvas (Ichneumonidae e Pteromalidae), conseguindo criálos em laboratório. Schöller (1999), estudando a biologia e ecologia de Cryptocephalus moraei e C. anceps, criou cinco espécies de parasitóides, obtidos a partir dos estágios

imaturos de C. moraei: Gelis acarorum, G. forticornis, Theroscopus esenbeckii (Ichneumonidae), Dimophora evanialis (Ichneumonidae) e Psilocera punctifrons (Pteromalidae). 


\subsection{Técnicas de criação de crisomelídeos}

São raros os trabalhos descrevendo técnicas de criação de Cryptocephalinae, portanto, a técnica de criação utilizada foi baseada nas informações disponíveis para a criação e manutenção de espécies de Chrysomelidae, principalmente com representantes que são pragas de importância agrícola, cujas técnicas de criação, em laboratório, têm se mostrado adequadas.

\subsubsection{Obtenção de ovos}

A criação de insetos, em laboratório, inicia-se com a obtenção de ovos e do controle da contaminação por microorganismos que pode impedir o desenvolvimento embrionário e, ainda, da presença de um substrato que permita o desenvolvimento dessa fase.

Diversos pesquisadores utilizaram diferentes materiais para desenvolver um substrato de postura: algodão úmido (Pecchioni, 1988), tecido tipo "gaze" umedecido (Gonzalez et al., 1982; Dominique \& Yule, 1983; Milanez, 1995; Abreur Neto, 1999; Ávila et al., 2000; Milanez \& Parra, 2000); papel (Herzog et al., 1974; Haji, 1981; Rajnauth et al., 1987); solo (Haji, 1981; Fisher et al., 1986; Heineck, 1993); areia autoclavada, papel filtro e "gaze" na cor negra umedecida (Silva-Werneck et al., 1995).

Chalfant \& Mitchell (1967) e Kirk et al., (1968) observaram que, em geral, os crisomelídeos preferem ovipositar em substratos úmidos, de coloração escura e, também, em solos com fissuras e partículas grossas (Milanez \& Parra, 2000). 
Para Milanez (1995) a utilização de tecido tipo "gaze" para a postura, facilita a coleta de ovos, pois a retirada é feita mergulhando-se o tecido em água ou através de lavagens sucessivas em água corrente (Ávila et al., 2000), substituindo-se a utilização do pincel que normalmente danifica os ovos (Herzog et al., 1974; Holcomb \& Fulton, 1978).

Diversos produtos químicos, em variadas concentrações, foram utilizados para o tratamento dos ovos de crisomelídeos para evitar a contaminação por fungos e bactérias. Marrone et al., (1985) testaram vários produtos e obtiveram êxito colocando os ovos em solução de Clorex (1\%) por cinco minutos, lavagem com água destilada e, após, em solução de ácido paracético $(0,25 \%)$ por dois minutos.

Herzog et al., (1974) e Gonzalez et al., (1982) utilizaram uma solução cúprica (1\%) durante cinco minutos. Holcomb \& Fulton (1978) trataram o substrato para postura com hipoclorito de sódio. O mesmo produto foi utilizado por Haji (1981), na concentração de (0,005\%); por Pecchioni (1988) e Milanez (1995) na concentração de $(0,05 \%)$ por dois minutos. Solução de sulfato cúprico na concentração de $1 \%$ foi usado por Milanez (1988).

\subsubsection{Desenvolvimento larval e pupal}

As fases imaturas caracterizam-se por serem mais frágeis, susceptíveis a microorganismos, especialmente fungos, e por sofrerem grande influência da falta ou do excesso de umidade dos substratos utilizados para a criação (Dominique \& Yule, 1983; Oloumi-Sadeghi \& Levine, 1989; Milanez, 1995). 
Os crisomelídeos, após completarem a fase larval, se dirigem ao solo onde constróem uma espécie de câmara para se transformarem em pré-pupa e, posteriormente, em pupa (Milanez, 1995). A sobrevivência das pupas é afetada quando elas são retiradas da câmara pupal, sofrendo a influência direta das condições do ambiente (Jackson, 1986).

O substrato padrão para criação de Diabrotica spp. têm sido plântulas de milho. Assim, Rimando et al., (1966) mantiveram larvas de D. virgifera em recipientes contendo vermiculita e plântulas de milho recém-germinadas.

Plântulas da planta hospedeira, tratadas com diferentes produtos químicos para evitar a contaminação, têm sido utilizadas na criação de várias espécies de crisomelídeos. Larvas de Cerotoma trifurcata foram criadas por Herzog et al. (1974) utilizando-se cotilédones de soja, feijão e caupi, tratados com uma solução de sulfato de cobre a 0,5\%; Holcomb \& Fulton (1978), trabalhando com a mesma espécie, utilizaram sementes germinadas de caupi tratadas com uma solução de hipoclorito de sódio a $10 \%$ e, como substrato, areia, solo, vermiculita e esterco, umedecido com água destilada e esterilizado.

Plântulas de milho e tubérculos de batatinha (Solanum tuberosum) foram utilizados por Haji (1981) para larvas de D. speciosa.

Gonzalez et al. (1982) alimentaram larvas de D. balteana e C. facialis com "seedlings" de milho e feijoeiro. Para a pupação utilizaram como substrato, areia fina umedecida colocada em placa de Petri. 
Dominique \& Yule (1983) criaram D. longicornis utilizando "seedlings" de milho para o desenvolvimento larval, em papel umedecido com água destilada. Para pupação, foi utilizado solo umedecido com água.

Fernandes (1986) utilizou sementes de feijão em placas de Petri, na criação de larvas de C. arcuata e Pecchioni (1988) alimentou larvas de D. speciosa com "seedlings" de milho e, para a pupação, utilizou como substrato, areia fina esterilizada e umedecida.

Larvas de D. speciosa foram alimentadas com plântulas de milho híbrido por Silva-Werneck et al. (1995) que utilizou, como substrato, solo arenoso autoclavado na proporção de $56 \%$ de areia, $16 \%$ de silte e $28 \%$ de argila.

Raízes seminais de milho pipoca foram utilizadas por Milanez (1995) para alimentar larvas de D. speciosa. Próximo ao final do terceiro ínstar, as larvas foram transferidas para uma bandeja de pupação com duas divisões. Uma divisão foi forrada com papel germiteste úmido, com sementes germinadas de milho, onde as larvas foram colocadas; na outra divisão, foi colocada uma mistura (1:1) de solo e areia fina úmida. No transcorrer da mudança de fase, as larvas locomoviam-se, através de orifícios, para a segunda divisão para pupar.

Salas (1998) utilizou sementes pré-germinadas de feijão para a alimentação de larvas de C. arcuata, em substrato contendo terra esterilizada. Pré-pupas e pupas foram colocadas em copos plásticos contendo mistura de terra, vermiculita e areia (2:1:1) e um chumaço de algodão umedecido diariamente. 
Vermiculita e papel germiteste foram utilizados como substrato, por Ávila (1999) para o estudo do desenvolvimento larval de D. speciosa. Para alimentar as larvas, o autor usou "seedlings" de milho.

Nava (2000) realizou estudos biológicos em laboratório e campo, com Cerotoma arcuatus, visando aperfeiçoar uma técnica de criação; verificou que a mais adequada foi aquela que utilizou plântulas de soja e vermiculita.

McFadyen (1987) estudou a especificidade hospedeira e biologia de Metallactus patagonicus, no Brasil, utilizando como planta hospedeira, folhas de Baccharis articulata (Asteraceae).

Reid (1999) realizou estudos com espécies de Cryptocephalinae, da Austrália; não obtendo sucesso na tentativa de criar esses insetos em laboratório. Segundo o autor a possível causa dessa dificuldade talvez esteja relacionada com a necessidade da presença de fungo ou bactéria, presente nas folhas do "litter", utilizadas para o desenvolvimento larval.

Schöller (1999) manteve as larvas do hospedeiro em "litter" de Hypericum perforatum (Clusiaceae), para obter hymenopteros parasitóides de Cryptocephalus sp., em laboratório.

\subsubsection{Fase adulta}

É necessário criar condições próximas às encontradas em ambiente natural, para que ocorra o desenvolvimento e a reprodução dos adultos. As criações de 
insetos em laboratório, normalmente utilizam diferentes tipos de gaiolas para impedir a fuga dos insetos e promover o acasalamento.

Skelton \& Hunter (1970) e Dominique \& Yule (1983) utilizaram gaiolas de alumínio com tela nas laterais para manter aeração, para adultos de $D$. undecimpunctata e D. longicornis, respectivamente.

Holcomb \& Fulton (1978) utilizaram como recipientes para acondicionamento de C. trifurcata, placas de Petri tendo o fundo forrado com papel filtro. Haji (1981) acondicionou os insetos coletados no campo em frascos de vidro transparentes, com a boca vedada por tecido "nylon", no seu interior colocou um papel de filtro umedecido.

Pecchioni (1988) utilizou para adultos de D. speciosa, frascos de vidro com um disco de papel no fundo para absorver a excessiva umidade e um tecido de "voil" como tampa.

Silva-Werneck et al. (1995) utilizaram gaiolas cilíndricas de acrílico, com tampa telada, para manter adultos de D. speciosa..

Salas (1998) manteve os adultos de C. arcuata em frascos de vidro tampados com tecido "voil", a fim de permitir a ventilação, em câmara climatizada. O fundo dos frascos foi forrado com papel filtro e, para auxiliar a manutenção da umidade, foi usando algodão, umedecido diariamente.

Milanez (1995) acondicionou os adultos de D. speciosa em gaiolas de acrílico de formato retangular, com duas aberturas laterais vedadas com tela de "nylon" para ventilação. 
Ávila (1999) utilizou gaiola de alumínio, com paredes de acrílico transparente na parte frontal e revestida lateralmente e posteriormente com tela de "nylon". Uma tela de "nylon" foi colocada no centro do fundo da gaiola para evitar o excesso de umidade e facilitar a limpeza.

\subsection{Condições controladas em laboratório}

Skelton \& Hunter (1970) mantiveram os adultos e o período de desenvolvimento embrionário com temperatura de $30,5{ }^{\circ} \mathrm{C}$ e umidade relativa de $72 \%$. Para o desenvolvimento larval a temperatura foi de $27^{0} \mathrm{C}$ e umidade relativa de $40-50 \%$.

Sutter et al., (1971), para o estudo de D. undecimpunctata em dieta artificial, utilizaram, para o desenvolvimento embrionário, temperatura de $26,5^{\circ} \mathrm{C}$ e umidade relativa de $75 \pm 5 \%$. Holcomb \& Fulton (1978) mantiveram a câmara de incubação para $C$. trifurcata com temperatura de $28^{\circ} \mathrm{C}$, umidade relativa de $60 \%$ e fotoperíodo de 24 horas.

Para estudar o ciclo vital de C. arcuata tingomariana Heineck \& Corseuil (1995) usaram temperatura de $26 \pm 2^{\circ} \mathrm{C}$, umidade relativa de $70 \pm 10 \%$ e fotofase de 14 horas.

Silva-Werneck et al., (1995) utilizaram, para todas as etapas de criação de D. speciosa, temperatura de $26 \pm 2^{0} \mathrm{C}$, umidade relativa de $70 \pm 10 \%$ e fotofase de 14 horas. Milanez (1995) e Ávila (1999) realizaram os estudos de laboratório com temperatura de $25 \pm 2{ }^{0} \mathrm{C}$, umidade relativa de $60 \pm 10 \%$ e fotofase de 14 horas, também para D. speciosa. 
McFadyen (1987) manteve a criação de Metallactus patagonicus em folhas de B. articulata, para realizar estudos sobre sua biologia, sob as condições ambientais de $15-25 \mathrm{C}$ e umidade relativa entre $70-90 \%$.

Para estudar os parasitóides de Cryptocephalus sp., Schöller (1999) manteve as larvas do hospedeiro em câmaras climatizadas à temperatura de $26^{\circ} \mathrm{C}$ e umidade relativa de $75 \%$. 


\section{MATERIAL E MÉTODOS}

A pesquisa foi desenvolvida no Laboratório de Entomologia Florestal do Departamento de Entomologia, Fitopatologia e Zoologia Agrícola, da Escola Superior de Agricultura "Luiz de Queiroz", em Piracicaba, São Paulo. Os experimentos foram desenvolvidos em câmara climatizada, tipo BOD mantida a temperatura de $25 \pm 1^{\circ} \mathrm{C}$, umidade relativa de $90 \pm 5 \%$ e fotofase de 14 horas, com a espécie Metallactus sp. (Coleoptera: Chrysomelidae: Cryptocephalinae), tendo como planta hospedeira, plântulas de Eucalyptus urophylla S. T. Blake.

\subsection{Avaliação dos parâmetros biológicos}

Os parâmetros biológicos observados foram:

Fase de ovo - período de incubação e viabilidade;

Fase de larva - duração, viabilidade e número de ínstares;

Fase de pupa - duração, viabilidade e peso da pupa;

Fase adulta - duração do ciclo total (ovo-adulto), duração dos períodos de préoviposição, oviposição, capacidade de postura, ritmo de postura, longevidade de machos e fêmeas, razão sexual e dimorfismo sexual. 


\subsection{Técnica de criação de Metallactus sp.}

Para os estudos do ciclo biológico foi necessário desenvolver uma técnica de criação adaptada de metodologias utilizadas e testadas para diversas espécies de crisomelídeos, principalmente pragas de agricultura, em condições de laboratório, já que não foram encontrados, na literatura, informações sobre métodos de criação de espécies do gênero Metallactus. Para as fases imaturas, a técnica de criação foi baseada na metodologia desenvolvida por Pecchioni (1988), Milanez (1995) e Ávila (1999), para criação de Diabrotica speciosa, com a utilização de plântulas da planta hospedeira para o desenvolvimento das larvas. Apenas um tratamento com plântulas, incluindo as raízes, de Eucalyptus urophylla, foi realizado.

Como substrato para a produção das plântulas foi utilizado húmus e palha de arroz carbonizada.

\subsubsection{Coleta de adultos no campo e a obtenção de ovos}

Para o estabelecimento da criação estoque foram coletados indivíduos adultos de Metallactus sp. em plantios comerciais de E. urophylla, na Fazenda Flecha Azul, de propriedade da RIPASA S/A, Papel e Celulose, na região de Boa Esperança do Sul, Estado de São Paulo, onde este inseto foi observado atacando ponteiros ou rebrotas de plantios recentes, com aproximadamente três meses de idade (Figura 1).

As coletas foram realizadas com rede entomológica e os insetos adultos foram transferidos para gaiolas cilíndricas de poliestireno transparente $(100 \mathrm{~mm}$ de 
diâmetro x $80 \mathrm{~mm}$ de altura), fechadas na parte inferior por uma tampa de PVC e, na parte superior, por uma tampa de PVC, revestida por uma tela plástica para aeração (Figura 2).

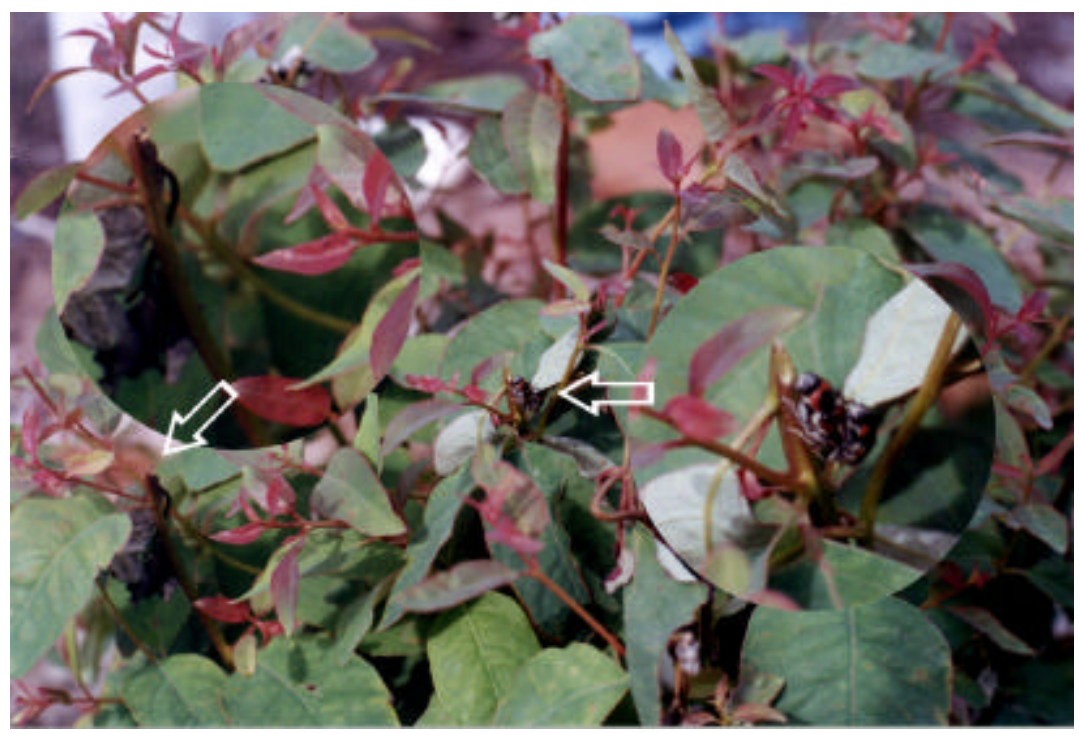

Figura 1 - Danos causados aos ponteiros de Eucalyptus urophylla, no campo, por adultos de Metallactus sp.

No interior da gaiola foi colocado um ponteiro de E. urophylla, em um recipiente com água, para manter a turgidez da planta e garantir a sobrevivência dos insetos, durante o transporte para o laboratório.

Os adultos coletados no campo (Figura 3) foram mantidos nas mesmas gaiolas cilíndricas de PVC, utilizadas na coleta, forradas com papel filtro umedecido com água destilada, além do ponteiro de E. urophylla para ser utilizado como alimento. 
Das fêmeas copuladas e casais que realizaram a cópula em laboratório, obteve-se os ovos necessários para dar início aos experimentos em laboratório.

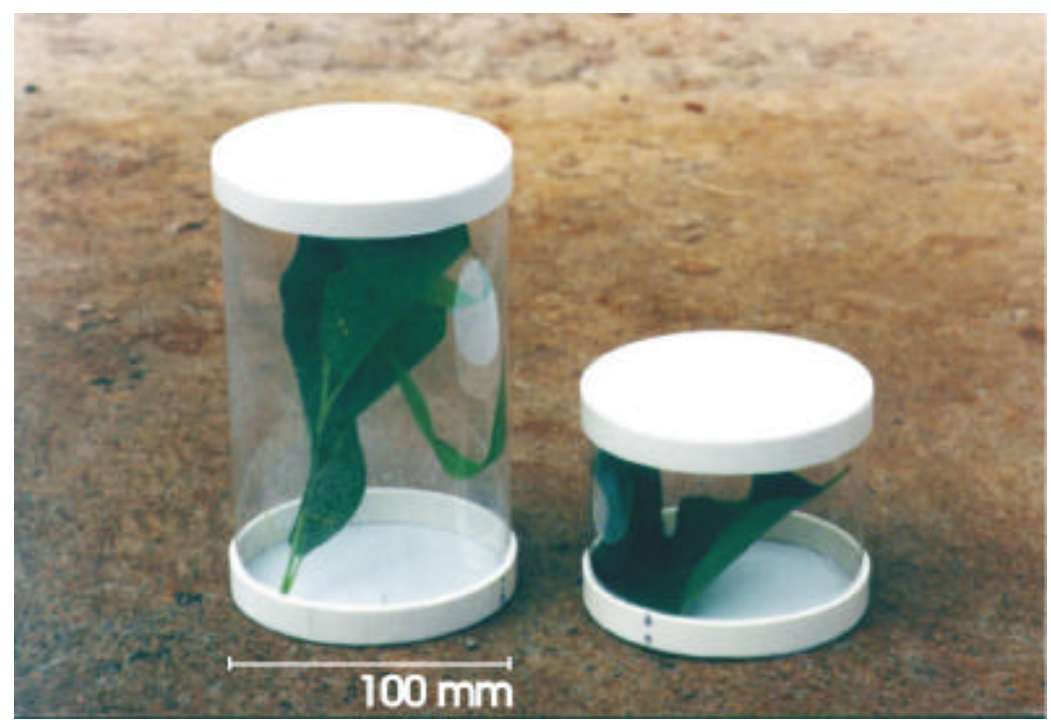

Figura 2 - Gaiola cilíndrica de poliestireno transparente (maior) para manutenção e transporte dos adultos de Metallactus sp.

Os ovos foram coletados (Figuras 4 e 5), com o auxílio de um pincel umedecido, e transferidos para placas de poliestireno transparente $(90 \mathrm{~mm}$ de diâmetro $\mathrm{x}$ $10 \mathrm{~mm}$ de altura) forradas com papel filtro umedecido com água destilada. As placas foram presas com elástico e mantidas em câmara climatizada, modelo BOD 347G, da FANEM, regulada a $25 \pm 1^{\circ} \mathrm{C}$, umidade relativa de $90 \pm 5 \%$ e fotofase de 14 horas, até a eclosão das larvas. 


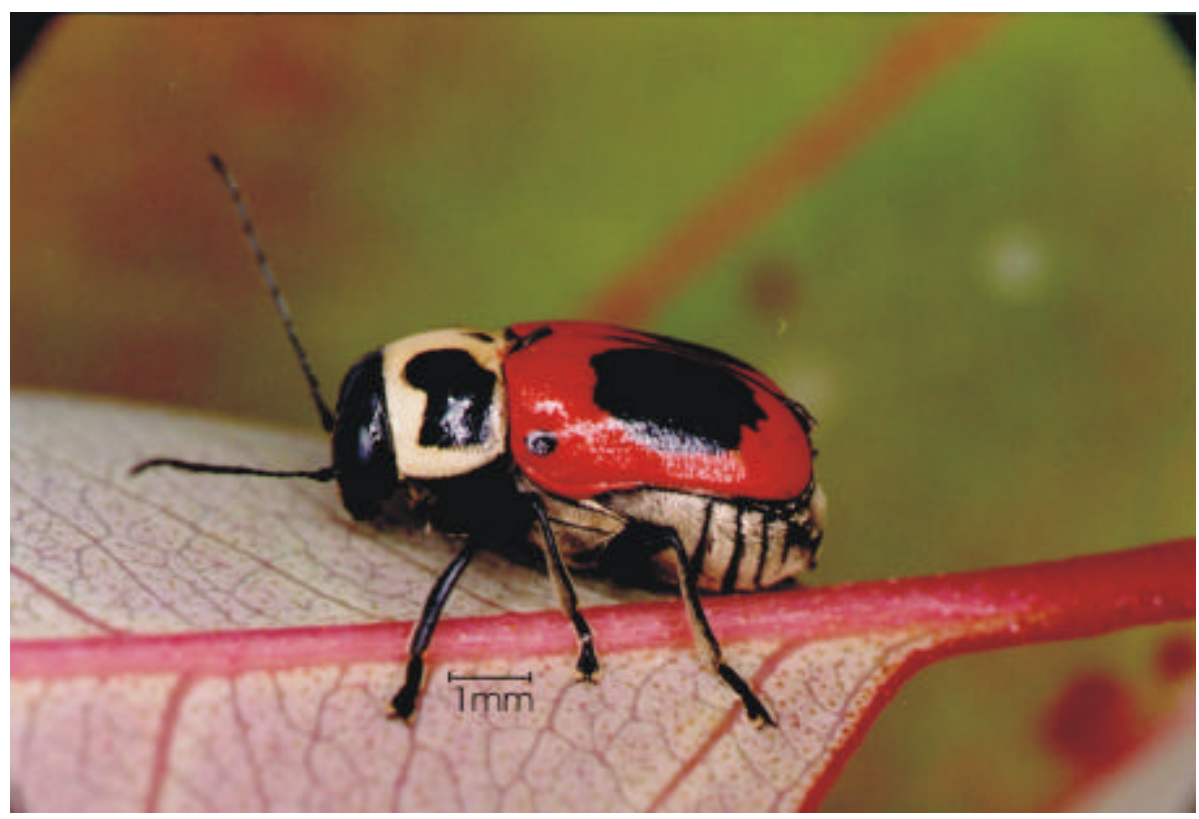

Figura 3 - Adulto de Metallactus sp. sobre folha de Eucalyptus urophylla 


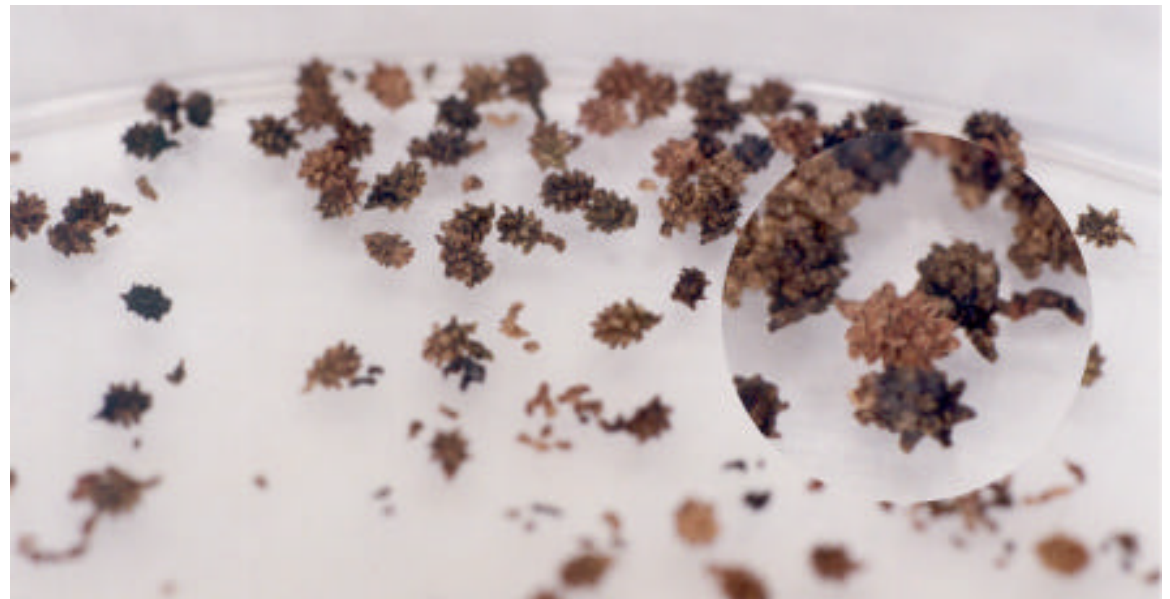

Figura 4 - Placa de poliestireno transparente contendo "egg-case", ovos e "pellets" de Metallactus sp.
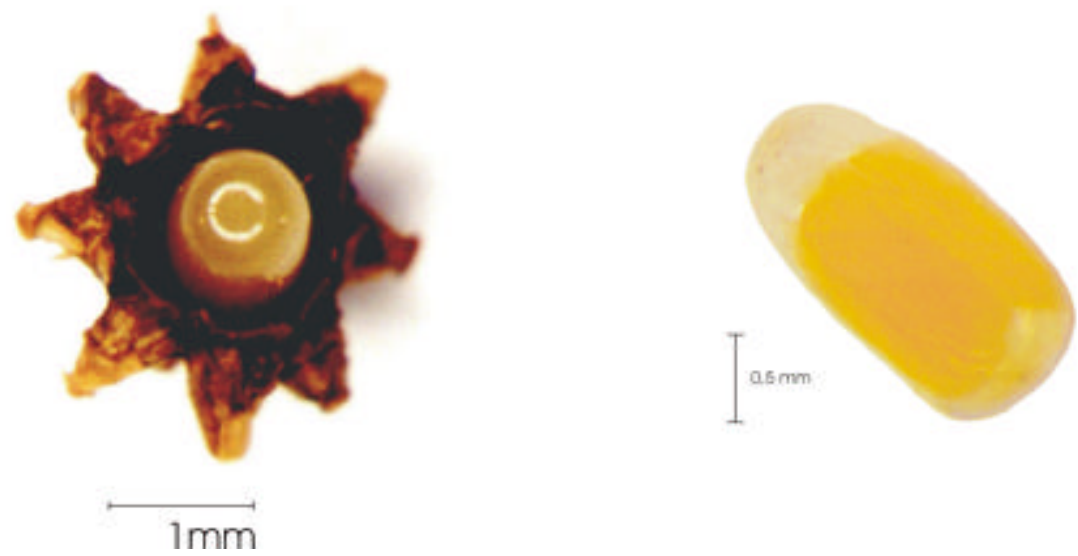

Figura 5 - "Egg-case" de Metallactus sp. aberta expondo o ovo (esquerda) e ovo sem a "egg-case" 


\subsubsection{Fase de larva}

Após alguns testes preliminares utilizando-se diferentes partes da planta hospedeira, como: folha madura, folha seca, caule, raízes, plântulas (com e sem raízes), optou-se por utilizar plântulas com raízes, devido a aceitação pelas larvas, nos testes realizados.

Plântulas de E. urophylla, em tubetes, com aproximadamente 30 a 45 dias de idade, foram utilizadas como planta hospedeira. Estas plântulas foram produzidas e fornecidas pelo viveiro de mudas florestais do Departamento de Ciências Florestais da ESALQ/USP.

Larvas recém-eclodidas foram distribuídas em 40 placas de poliestireno transparente (90 mm de diâmetro x $10 \mathrm{~mm}$ de altura), forradas com papel filtro umedecido, sendo colocadas cinco larvas por placa. Estas foram mantidas em câmaras climatizadas reguladas nas mesmas condições já citadas, até que atingissem a fase de pupa.

As plântulas de E. urophylla, inclusive com raízes, foram retiradas dos tubetes, lavadas em água corrente e colocadas nas placas, sobre o papel filtro umedecido. As placas foram vistoriadas, o papel filtro trocado diariamente e as plântulas trocadas a cada dois dias.

Para a determinação do número de ínstares foi medida, diariamente, a largura da cápsula cefálica de 30 larvas, por meio de uma ocular micrométrica modelo WILD MMS 235, acoplada a um microscópio estereoscópico. Após a medição, em um 
mesmo aumento do microscópio estereoscópico, recorreu-se a uma lâmina micrométrica, para se fazer a conversão em milímetros, no respectivo aumento.

A medição da cápsula cefálica foi realizada até o momento em que a larva vedava hermeticamente a escatoteca, com uma tampa, quando então, considerourse o início do período de pré-pupa.

Para a determinação do número de ínstares utilizoutse a curva multimodal de freqüências para as cápsulas cefálicas, na formulação das hipóteses a serem testadas no modelo linearizado da regra de Dyar, através do software Mobae (Modelos Bioestatísticos para a Entomologia) (Haddad et al., 1995).

A larva tem o hábito de proteger-se dentro da escatoteca (Figuras 6 e 7), ao sentir-se ameaçada, vedando a abertura com a estrutura chanfrada que apresenta na cabeça, impedindo a medição da cápsula cefálica. As larvas retiradas da escatoteca não sobreviveram mais que 72 horas, fora da estrutura de proteção.

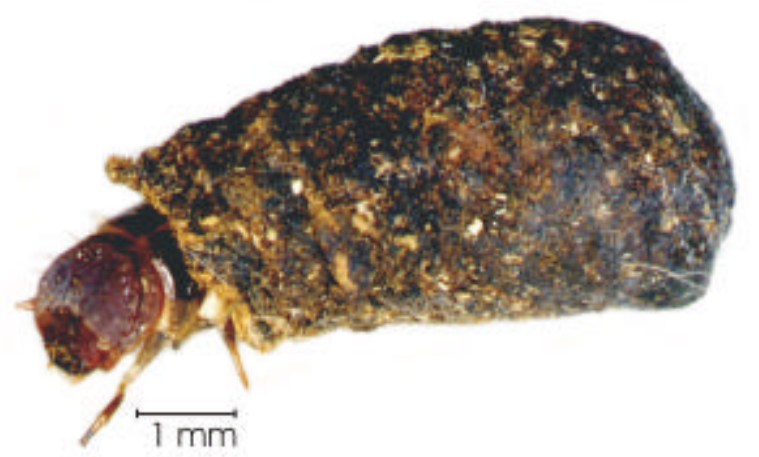

Figura 6 - Larva de último ínstar de Metallactus sp. com cabeça e pernas projetadas para fora da escatoteca, para locomoção 
Para realizar a medição da cápsula cefálica, foi necessário utilizar-se de um artifício que possibilitasse, por alguns segundos, que a larva mantivesse a cabeça fora da escatoteca, sem que fosse necessário, retirá-la da mesma e sem provocar algum tipo de dano que impossibilitasse o seu desenvolvimento.
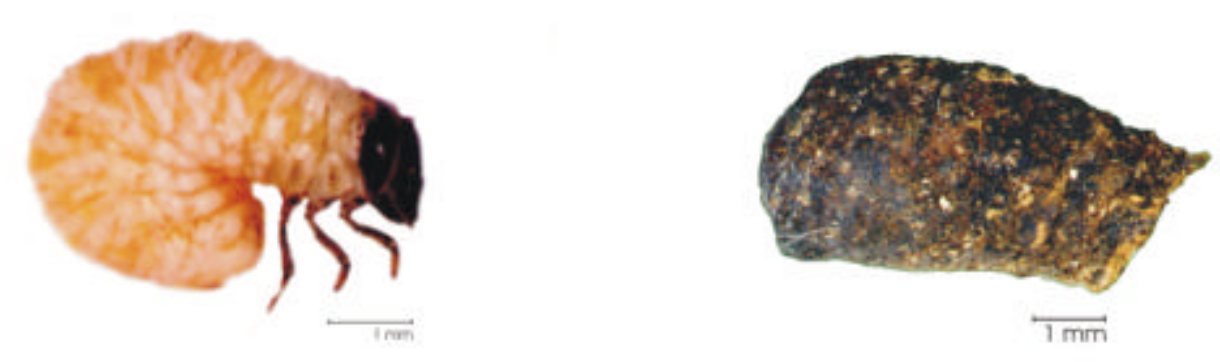

Figura 7. Larva madura de Metallactus sp. fora da escatoteca. À direita e escatoteca em vista lateral.

A técnica testada consistiu em retirar a escatoteca da placa de Petri onde a larva se desenvolvia, com o auxílio de uma pinça e colocá-la em outra placa de Petri forrada com papel filtro. No interior dessa placa a escatoteca era imersa em uma película de água destilada, aos poucos, até que a água atingisse a larva, no interior da escatoteca.

Após um breve período, depois da película de água invadir a escatoteca e, causar algum desconforto à larva, esta projetava a cabeça e os três pares de pernas para fora da estrutura de proteção, locomovendo-se com a intenção de abandonar o local. $\mathrm{Na}$ 
posição normal, isto é, com as pernas tocando a superfície do papel filtro, a larva se locomovia, juntamente com a escatoteca. Com a movimentação da larva, a leitura da medição era extremamente demorada e imprecisa. Para impedir a movimentação da larva e, conseqüentemente, possibilitar a leitura da medição, a larva foi mantida na posição invertida, isto é, com as pernas para cima, com o auxílio de uma pequena pinça.

Ao sentir-se incomodada com a água no interior da escatoteca e a posição invertida, a larva movimentava-se, na tentativa de voltar à posição normal e, após alguns segundos, mantinha a cabeça para fora da escatoteca por tempo suficiente para que permitisse a leitura da medição da cápsula cefálica. Após a medição, a larva era colocada na posição normal e com o auxílio de uma pinça era devolvida à placa Petri correspondente.

Algumas vezes, principalmente antes da mudança de ínstar, as larvas demoravam para deixar a escatoteca, obrigando a interrupção do processo de medição, pois havia o perigo da larva morrer.

\subsubsection{Fase de pupa}

No final da fase larval, a larva constrói uma tampa para fechar a escatoteca hermeticamente. Essa tampa é diferente da tampa construída antes da muda, pois apresenta uma consistência mais sólida, semelhante ao restante do material utilizado para a construção da escatoteca (Figura 8). No interior da escatoteca selada, após inverter de posição, ou seja, a cabeça da larva ficar oposta à abertura da escatoteca (Figura 9), a larva passa para a fase de pré-pupa e logo em seguida para a fase de pupa. 

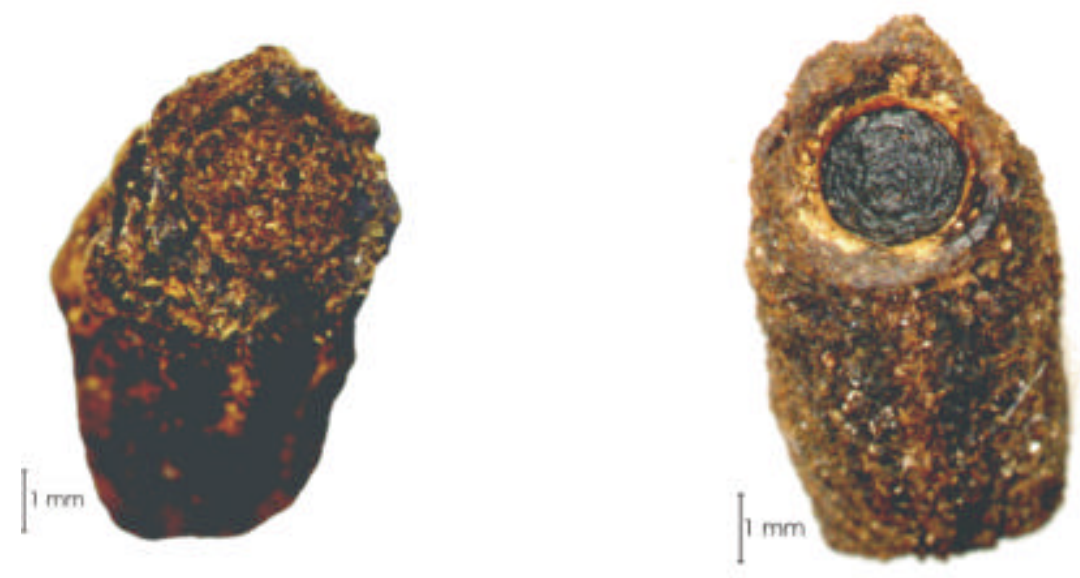

Figura 8 - Escatotecas de Metallactus sp. com tampa provisória (esquerda) e com tampa definitiva

Como o processo ocorre no interior da escatoteca, é muito difícil determinar a duração da fase de pré-pupa e pupa, sem retirar a estrutura de proteção, o que provocaria a morte do inseto, além da necessidade do acompanhamento do desenvolvimento até a emergência do adulto. Os indivíduos que foram retirados da escatoteca, para acompanhar o processo e determinar o período de pré-pupa e pupa, não sobreviveram. 
Algumas escatotecas foram abertas em diferentes datas e nelas foram encontradas pré-pupas, onde a larva mantinha-se numa posição "curvada", sem apresentar mobilidade, cor avermelhada e aspecto enrugado. Também foram observadas pupas que apresentavam coloração com tonalidade "creme". As pupas são do tipo livre ou exarada (Figura 10 ).
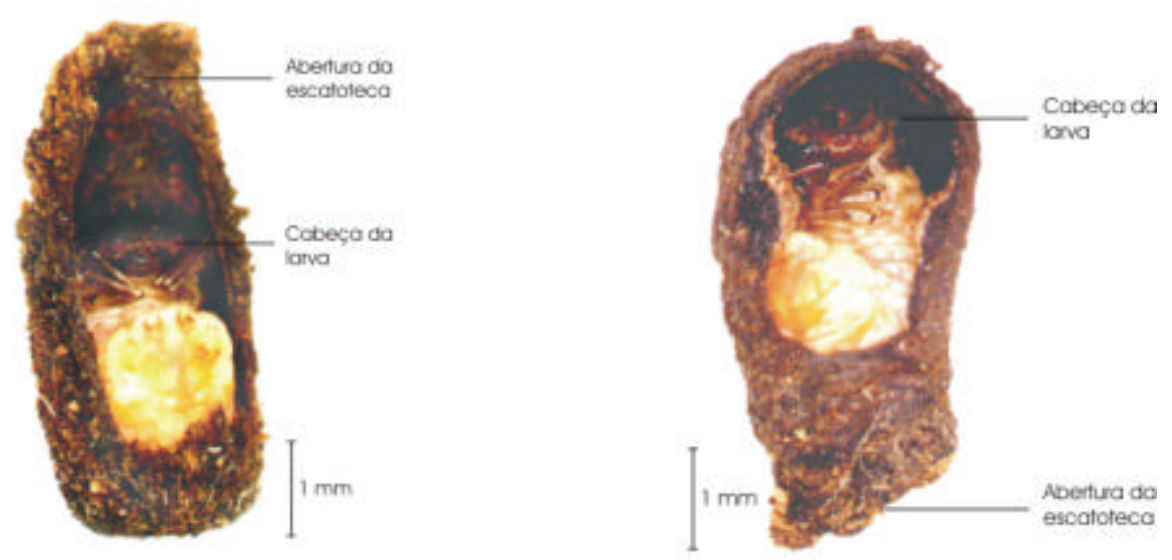

Figura 9 - Escatotecas de Metallactus sp. contendo a larva na posição normal (esquerda) e em posição invertida, para pupação 

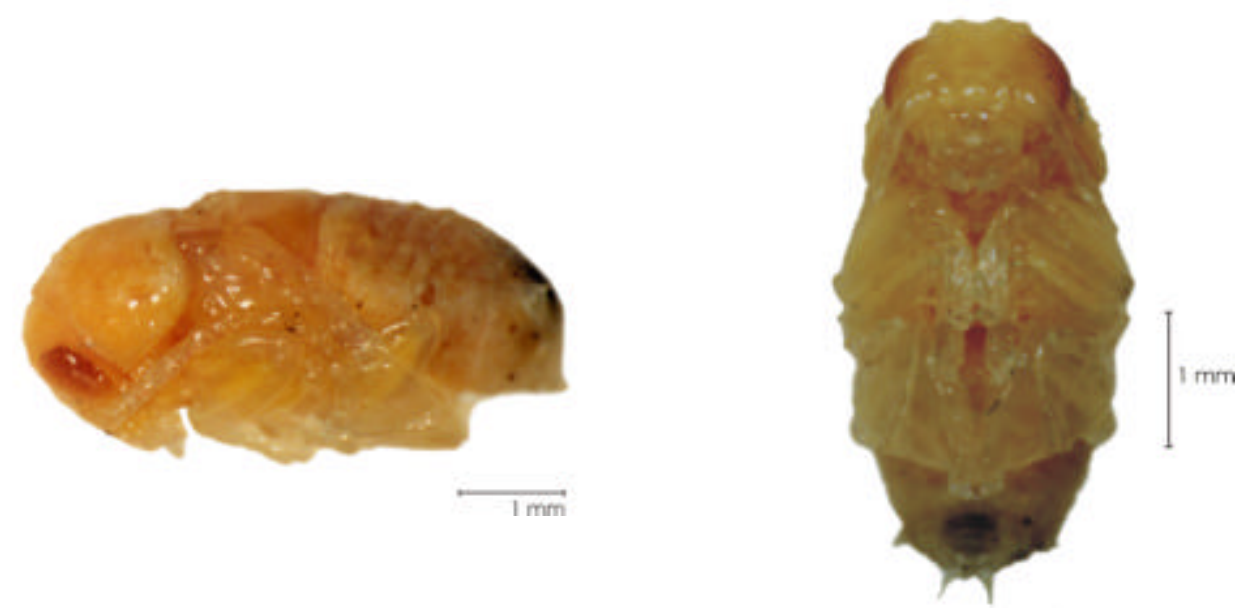

Figura 10 - Pupas de Metallactus sp. em vista lateral (esquerda) e ventral

O conjunto (pupa-escatoteca) foi pesado, em balança de precisão, após a escatoteca apresentar-se selada, pois visualmente, apresentavam diferenças significativas no tamanho, o que poderia indicar tamanhos diferentes para machos e fêmeas.

\subsubsection{Fase adulta}

Para a obtenção de dados de longevidade dos adultos e da fecundidade, 19 casais (emergidos no mesmo dia), foram analisados, sendo que a separação por sexo baseou-se nas diferenças observadas, nos últimos segmentos abdominais (Figura 11). Os casais foram isolados em gaiolas cilíndricas de poliestireno transparente $(100 \mathrm{~mm}$ de 
diâmetro x $80 \mathrm{~mm}$ de altura), com a parte inferior fechada por uma tampa de PVC e a parte superior fechada por uma tampa de PVC com uma tela de "nylon", para aeração .
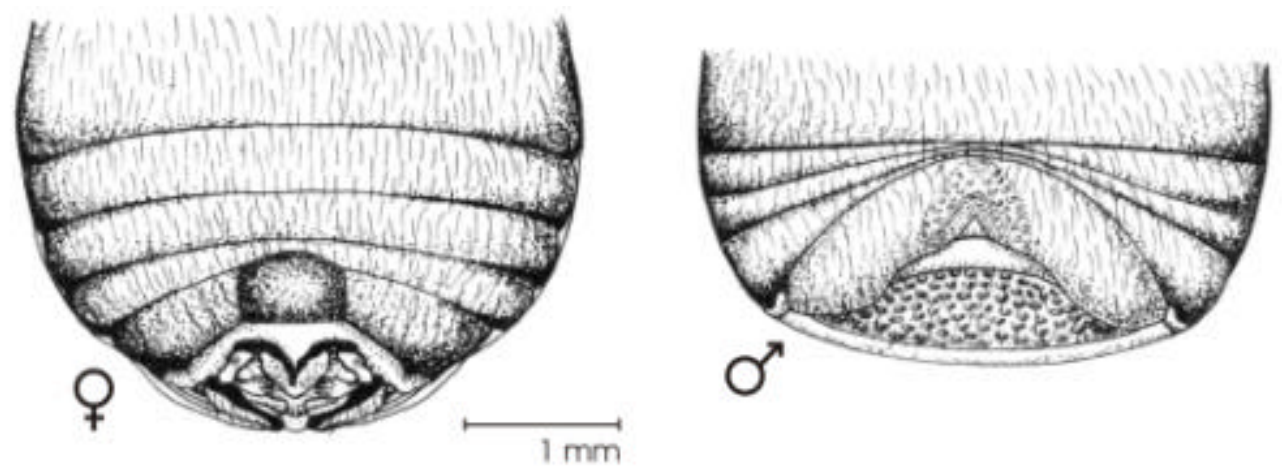

Figura 11 - Dimorfismo sexual de adultos de Metallactus sp. mostrando as diferenças nos últimos segmentos abdominais (vista ventral)

Os adultos foram alimentados com plântulas de E. urophylla, mantidas túrgidas em um recipiente com água, colocados no interior da gaiola e trocadas diariamente. Como substrato para oviposição foi colocado papel filtro umedecido, na base da gaiola, trocado a cada dois dias.

Foram observados:

* número de ovos colocados por fêmea/dia;

* número total de ovos/fêmea;

* longevidade de machos e fêmeas;

* período de pré-oviposição;

* período de oviposição; 


\subsubsection{Razão sexual}

A razão sexual foi calculada segundo a fórmula:

$$
\mathbf{r}_{\mathbf{s}}=\frac{\mathrm{n}^{\mathrm{o}} \text { de fêmeas }}{\mathrm{n}^{\mathrm{o}} \text { de machos }+\mathrm{n} \text {-o de fêmeas }}
$$

\subsubsection{Tabela de vida de fertilidade}

A partir dos dados biológicos obtidos foi elaborada a tabela de vida de fertilidade, sendo que os valores das colunas $\mathrm{x}, \mathrm{m}_{\mathrm{x}} \mathrm{e} \mathrm{l}_{\mathrm{x}} \mathrm{e}$ os índices $\mathrm{R}, \mathrm{T}, \mathrm{T}_{\mathrm{m}} \mathrm{e} \lambda$ foram calculados segundo Silveira Neto et al. (1976), como descrito a seguir:

$\mathbf{x}=$ intervalo de tempo no qual foi tomada a amostra;

$\mathbf{m}_{\mathbf{x}}=$ fertilidade específica (número de descendentes produzidos no estágio por fêmea e que darão fêmeas; é portanto, calculada em função da razão sexual);

$\mathbf{l}_{\mathbf{x}}=$ taxa de sobrevivência no intervalo de amostragem.

Com base nestes dados, foram calculados os índices:

$\mathbf{R o}=$ taxa líquida de reprodução, onde:

$$
\mathbf{R o}=\Sigma \mathbf{m}_{\mathbf{x}} \cdot \mathbf{l}_{\mathbf{x}}
$$

$\mathbf{T}=$ duração média de uma geração, onde:

$$
\mathbf{T}=\boldsymbol{\Sigma} \mathbf{m}_{\mathrm{x}} \cdot \mathbf{l}_{\mathrm{x}} \cdot \mathbf{x} / \mathbf{R o}
$$

$\mathbf{r}_{\mathbf{m}}=$ capacidade de aumentar em número, onde:

$$
r_{m}=\log \operatorname{Ro} / T
$$

$\boldsymbol{\lambda}=$ razão finita de aumento, onde:

$$
\lambda=\mathrm{e}^{\mathrm{m}}
$$




\section{RESULTADOS E DISCUSSÃO}

\subsection{Identificação da espécie}

O pesquisador Matthias Schöller, especialista em sistemática e ecologia de coleópteros da família Chrysomelidae, subfamília Cryptocephalinae, do "Biologische Beratung Berlin", constatou tratar-se de uma nova espécie, a qual foi descrita como Metallactus mosei (Schöller, 2003).

\subsection{Técnica de criação de Metallactus sp.}

A metodologia de criação, utilizada para as fases imaturas, permitiu acompanhar o desenvolvimento do ciclo biológico do Metallactus sp., além da elaboração de uma técnica de criação, em laboratório (Figura 12).

As larvas recém-eclodidas, provenientes das placas de Petri (local de incubação), eram transferidas para outras placas semelhantes, revestidas com papel filtro umedecido, que continham plântulas de E. urophylla. As plântulas (incluindo as raízes) eram retiradas dos tubetes, tendo as raízes lavadas em água corrente, antes de serem utilizadas. 
Durante o desenvolvimento larval, as placas de Petri eram vistoriadas diariamente, sendo o papel filtro trocado e as plântulas substituídas a cada dois dias. Após as escatotecas serem seladas de maneira definitiva (indicando o início dos períodos de pré-pupa e pupa), as mesmas eram pesadas em balança de precisão e individualizadas em placas de Petri, revestida com papel filtro.

Com a emergência dos adultos, eram formados os casais e transferidos para gaiolas de oviposição (de PVC/poliestireno transparente), sendo estes também alimentados com plântulas de E. urophylla e mantidos em câmaras climatizadas. 
Método de criação de Metallactus sp.

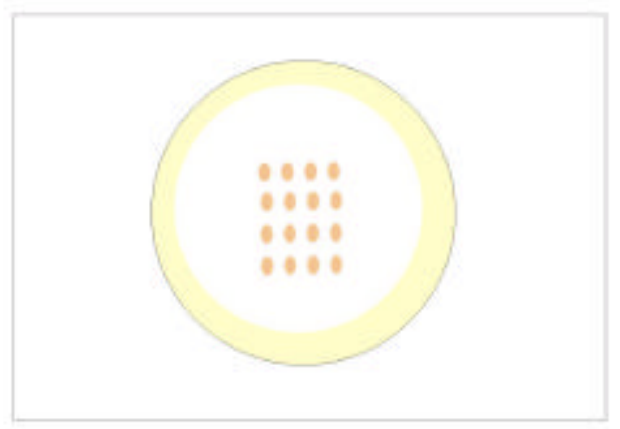

1- Placa de poliestireno transparente contendo papel filtro umedecido para o desenvolvimento embrionário.

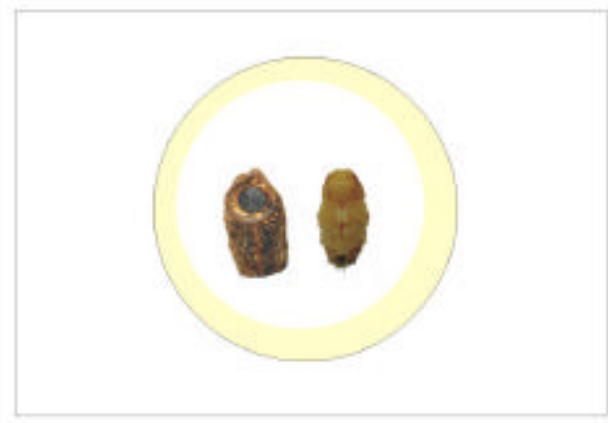

3 - Placa de poliestireno transparente contendo papel filtro umedecido para o desenvolvimento pupal.

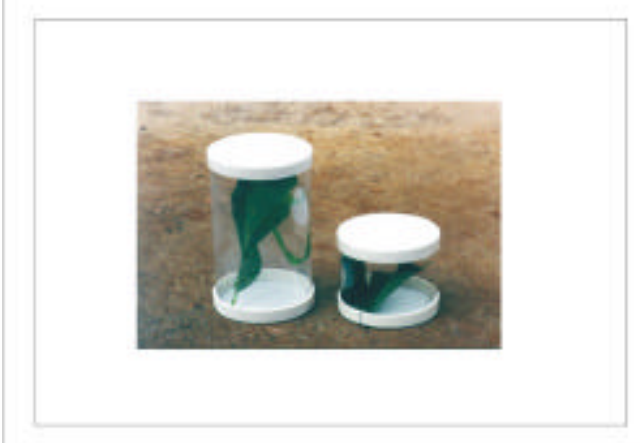

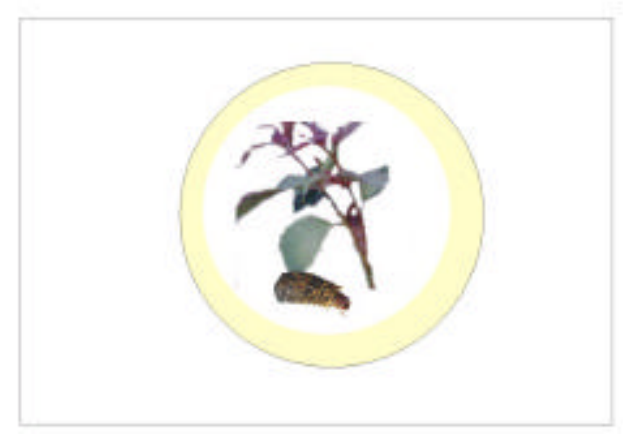

2 - Placa de poliestireno transparente contendo papel filtro umedecido $e^{\text {"seedlings" }}$ de E. urophylla, para o desenvolvimento larval.

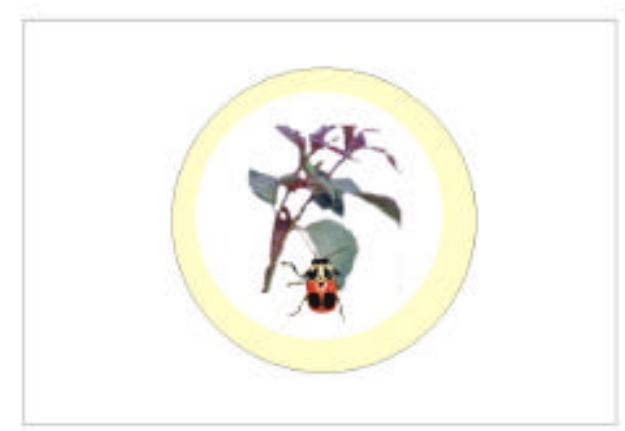

4 - Base da gaiola para acasalamento e postura contendo papel filtro umedecido e "seedlings" de E. Urophylla, para alimentação dos adultos..

5 - Gaiolas para manutenção (maior) e para acasalamento e postura (menor) de PVC/poliestireno.

Figura 12 - Técnica de criação de Metallactus sp. em Eucalyptus urophylla 


\subsection{Biologia de Metallactus sp.}

\subsubsection{Duração e viabilidade da fase larval}

A duração da fase larval de Metallactus sp., foi de 124,81 -26,35 dias, em média, apresentando uma variação de 86 a 190 dias e a viabilidade foi de 70,56\%, Os dados obtidos estão de acordo com o resultado obtido por McFadyen (1987), que foi de 180 dias, para Metallactus patagonicus, criado em Baccharis articulata (Asteraceae).

\subsubsection{Número de ínstares}

Foram seis os ínstares de Metallactus sp., sendo a mudança de cada ínstar caracterizada pelos "picos" definidos de larguras de cápsulas cefálicas, como mostra a Tabela 1 e o gráfico da Figura 13. A duração de cada ínstar é mostrada na Tabela 2.

Os valores médios da largura das cápsulas cefálicas para os 6 ínstares foram de 0,$40 ; 0,53 ; 0,67 ; 0,78 ; 1,00$ e $1,27 \mathrm{~mm}$ para o primeiro, segundo, terceiro, quarto, quinto e sexto ínstares, respectivamente. Verificou-se que o crescimento da cápsula cefálica das larvas seguiu a regra de Dyar, estando o valor da razão de crescimento $(1,27)$ entre 1,1 e 1,9 . O coeficiente de correlação foi de 0,99 , apresentando alto grau de confiabilidade (Tabela 1). 
Tabela 1. Largura média da cápsula cefálica, constante de Dyar e coeficiente de correlação de Metallactus sp., mantido em plântulas de Eucalyptus urophylla. Temp.: $25 \pm 1{ }^{\circ} \mathrm{C}$; UR: $90 \pm 5 \%$ e fotofase: 14 horas.

\begin{tabular}{cccccccc}
\hline \multicolumn{4}{c}{ Largura Média da Cápsula Cefálica $(\mathrm{mm})$} & \multicolumn{2}{c}{$\begin{array}{c}\text { Constante } \\
\text { de } \\
\text { Dyar }\end{array}$} & \multicolumn{2}{c}{$\begin{array}{c}\text { Coeficiente } \\
\text { de } \\
\text { correlação }\end{array}$} \\
\hline $1^{\circ}$ instar & $2^{\circ}$ instar & $3^{\circ}$ instar & $4^{\circ}$ instar & $5^{\circ}$ instar & $6^{\circ}$ instar & $(\mathrm{K})$ & $\left(\mathrm{R}^{2}\right)$ \\
0,40 & 0,53 & 0,67 & 0,78 & 1,00 & 1,45 & 1,27 & 0,99 \\
\hline
\end{tabular}

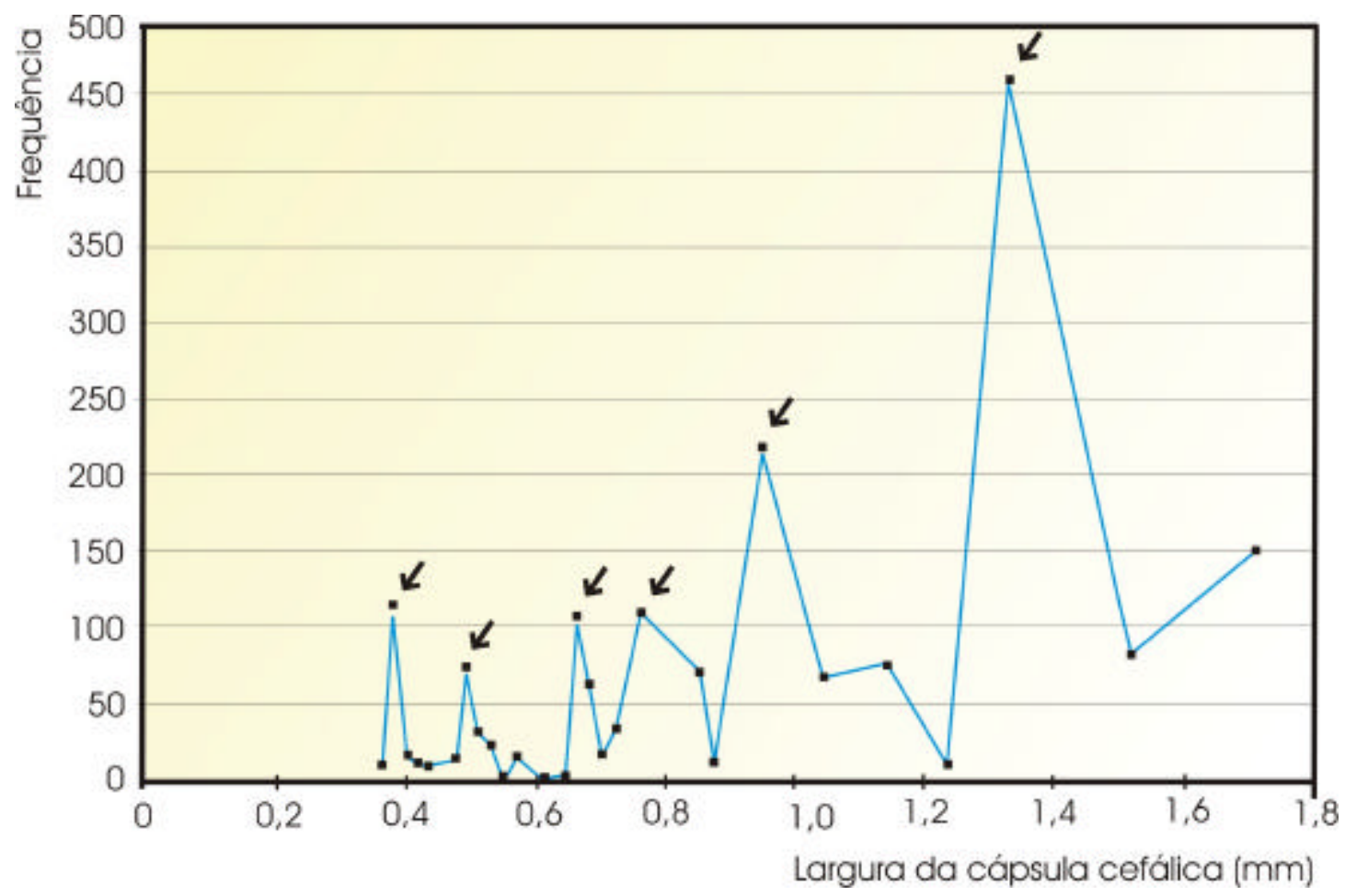

Figura 13 - Curva de distribuição de freqüências de larguras de cápsulas cefálicas de larvas de Metallactus sp., mantidas em Eucalyptus urophylla. As setas indicam os ínstares. Temp.: $25 \pm 1^{\circ} \mathrm{C}$; UR: $90 \pm 5 \%$ e fotofase: 14 horas 
Tabela 2. Duração média dos ínstares de Metallactus sp.. Temp.: $25 \pm 1{ }^{\circ} \mathrm{C}$; UR: $90 \pm 5 \%$ e fotofase: 14 horas.

\begin{tabular}{cc}
\hline Instar & Duração (dias) \pm Desvio Padrão \\
\hline I & $9,19 \pm 1,86$ \\
II & $10,69 \pm 4,76$ \\
III & $18,05 \pm 6,71$ \\
IV & $15,95 \pm 7,65$ \\
V & $52,23 \pm 18,80$ \\
VI & $59,50 \pm 19,90$ \\
\hline
\end{tabular}

\subsubsection{Duração e viabilidade dos períodos de pré-pupa e pupa}

A pupação ocorre no interior da escatoteca, após esta ser selada pela larva. Pela impossibilidade de ser feita a avaliação dos períodos de pré-pupa e pupa, separadamente, para não comprometer a sobrevivência da pupa, caso fosse retirada do interior da escatoteca; passou-se a considerar o início dos períodos de pré-pupa e pupa, a partir do momento que a larva lacrou a escatoteca de forma definitiva.

A duração dos períodos de pré-pupa e de pupa observado foi de

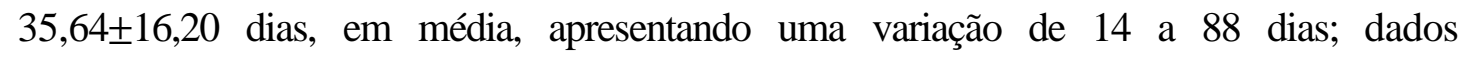
similares aos apresentados por McFayden (1987), para M. patogenicus, que obteve uma duração de 30 dias.

Foi observado que $58,27 \%$ das pupas interromperam o seu desenvolvimento, não ocorrendo a emergência do adulto. Devido à interrupção do desenvolvimento de um número considerável de pupas, a viabilidade desse período foi de $37,79 \%$. 


\subsubsection{Fase adulta}

A emergência dos adultos ocorre através da extremidade posterior àquela da abertura da escatoteca selada, após o adulto recortar uma tampa (Figura 14). Essa característica já havia sido citada LeSage (1984) e por McFayden (1987). Schöller (1999) esquematizou como ocorre a emergência do coleóptero.

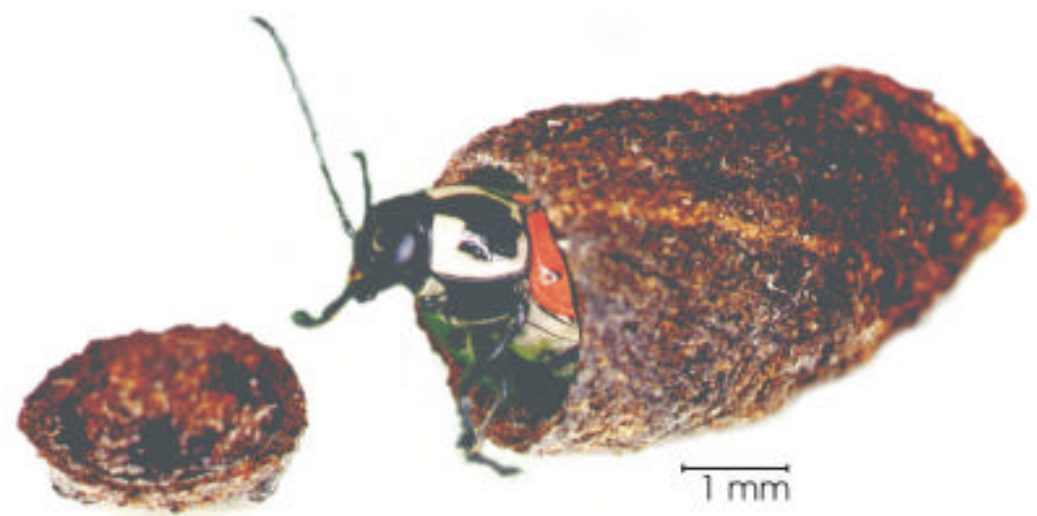

Figura 14 - Emergência de Metallactus sp. através da retirada de uma tampa do lado oposto à abertura da escatoteca

\subsubsection{Períodos de pré-oviposição e oviposição}

O período médio de pré-oviposição de adultos Metallactus sp. em $E$.

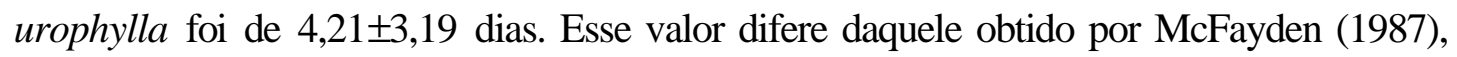
que foi bem mais longo e igual a 12 dias, para M. patagonicus. No entanto, com relação 
ao período de postura de 117,26 dias, com valor muito próximo àquele obtido por McFayden (1987), que foi de 114 dias.

\subsubsection{Fecundidade}

A produção de ovos em E. urophylla foi, em média, de 687,11 $\pm 252,95$ ovos/fêmea no período médio de 117,26 -38,67 dias, com uma variação de 126 a 1158 ovos/fêmea. O período com maior concentração de postura foi observado entre a $2^{\mathrm{a}}$ e a $6^{a}$ semana de postura, representando $42,93 \%$ do total de ovos colocados (Tabela 3).

Os dados observados nesta pesquisa diferem dos de McFayden (1987), para M. patogenicus que foi em média de 234,5 ovos/fêmea, com uma variação de 29 a 510 ovos.

\subsubsection{Longevidade}

A longevidade de adultos de Metallactus sp. diferiu em função do sexo,

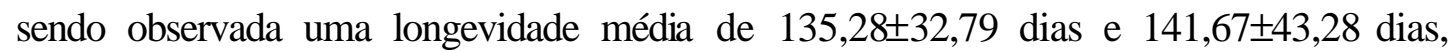
para fêmeas e machos, respectivamente (Tabela 3). O resultado da longevidade média de fêmeas, foi discrepante em relação ao valor obtido por McFayden (1987) para $M$. patogenicus, que foi em média de 118 dias; esse autor não observou a longevidade dos machos. As diferenças encontradas, podem ser atribuídas aos diferentes métodos empregados na criação de adultos e às condições de laboratório utilizadas. 
Tabela 3. Fecundidade e longevidade de fêmeas de Metallactus sp. $(\mathrm{N}=19)$

\begin{tabular}{lcc}
\hline Parâmetros Biológicos & Média \pm desvio padrão & Intervalo de Variação \\
\hline Longevidade (dias) & $135,38 \pm 32,79$ & $(77-169)$ \\
Período reprodutivo (dias) & $117,26 \pm 38,67$ & $(28-160)$ \\
№ de ovos/fêmea & $687,11 \pm 252,95$ & $(126-1158)$ \\
\hline
\end{tabular}

\subsubsection{Razão sexual}

A análise dos dados indicou uma razão sexual de 0,52. Esse valor está coerente com os resultados obtidos por McFayden (1987), que estudou M. patogenicus, na região sul do Brasil, observando uma razão média igual a 0,5.

\subsubsection{Peso das pupas (escatoteca + pupa)}

Foi evidente a variação observada entre os pesos das escatotecas. $\mathrm{O}$ peso médio (escatoteca + pupa) foi igual a 0,077 $\pm 0,014 \mathrm{mg}$, variando de 0,05 a $0,11 \mathrm{mg}$, nas que originam machos, e 0,1108 $\pm 0,022 \mathrm{mg}$, variando de 0,08 a $0,16 \mathrm{mg}$, nas que originam fêmeas. Esta variação parece ter uma correlação com o tamanho dos insetos adultos, pois na sua grande maioria, as fêmeas apresentaram tamanhos maiores que os machos. Schöller (1999) verificou que as escatotecas de machos de Cryptocephalus moraei, no último ínstar larval, apresentaram-se bem menores, em comparação àquelas 
das fêmeas. Para o autor, poderia ser parcialmente definido o sexo dos indivíduos, através desta diferenciação apresentada pela escatoteca.

\subsubsection{Tabela de vida de fertilidade}

A duração média de uma geração (T), ou seja, o período de tempo decorrido entre o nascimento dos pais e o de seus descendentes foi de 32,30 semanas.

A capacidade de aumento populacional da espécie a cada geração, estimada através da taxa líquida de reprodução (Ro), foi de 33,24.

Analisando a Tabela 4, observa-se que o período mais favorável para o desenvolvimento populacional da espécie, situou-se entre as $27^{\text {a }}$ e $29^{\mathrm{a}}$ semanas do ciclo, pois obteve-se maior valor para a fertilidade específica. 
Tabela 4. Tabela de vida de fertilidade para Metallactus sp., criado em plântulas de Eucalyptus urophylla. Temp.: $25 \pm 1{ }^{\circ} \mathrm{C}$; UR: $90 \pm 10 \%$ e fotofase de 14 horas.

\begin{tabular}{|c|c|c|c|c|c|}
\hline x (semanas) & $\mathrm{m}_{\mathrm{x}}$ & $1_{x}$ & $m_{x} \cdot l_{x}$ & $m_{x} \cdot l_{x} \cdot \mathrm{x}$ & Fase \\
\hline 0,5 & - & 1,0 & & & \\
\hline 1,5 & - & 0,90 & & & \\
\hline \multicolumn{6}{|l|}{2,5} \\
\hline 3,5 & & & & & ovo, larva, \\
\hline 4,5 & & 0,7 & & & pupa \\
\hline \multicolumn{6}{|l|}{ : } \\
\hline \multicolumn{6}{|l|}{19,5} \\
\hline \multicolumn{6}{|l|}{ : } \\
\hline 24,5 & & & & & pré-oviposição \\
\hline 25,5 & 2,84 & 0,70 & 1,98 & 50,49 & \\
\hline 26,5 & 4,09 & 0,66 & 2,69 & 71,28 & \\
\hline 27,5 & 4,32 & 0,66 & 2,85 & 78,37 & \\
\hline 28,5 & 4,69 & 0,66 & 3,09 & 88,06 & \\
\hline 29,5 & 4,80 & 0,63 & 3,02 & 89,09 & \\
\hline 30,5 & 4,16 & 0,63 & 2,62 & 79,91 & \\
\hline 31,5 & 2,50 & 0,63 & 1,57 & 49,45 & \\
\hline 32,5 & 3,00 & 0,63 & 1,89 & 61,42 & \\
\hline 33,5 & 3,21 & 0,63 & 2,02 & 67,67 & \\
\hline 34,5 & 3,17 & 0,59 & 1,87 & 64,51 & \\
\hline 35,5 & 3,19 & 0,59 & 1,88 & 66,74 & \\
\hline 36,5 & 2,53 & 0,59 & 1,49 & 54,38 & adultos \\
\hline 37,5 & 2,59 & 0,55 & 1,42 & 53,25 & \\
\hline 38,5 & 2,03 & 0,55 & 1,12 & 43,12 & \\
\hline 39,5 & 1,58 & 0,51 & 0,80 & 31,60 & \\
\hline 40,5 & 1,51 & 0,48 & 0,72 & 29,16 & \\
\hline 41,5 & 1,55 & 0,44 & 0,68 & 28,22 & \\
\hline 42,5 & 1,38 & 0,40 & 0,55 & 23,37 & \\
\hline 43,5 & 1,35 & 0,29 & 0,39 & 16,96 & \\
\hline 44,5 & 1,24 & 0,22 & 0,27 & 12,01 & \\
\hline 45,5 & 1,22 & 0,18 & 0,22 & 10,01 & \\
\hline 46,5 & 0,91 & 0,11 & 0,10 & 4,65 & \\
\hline \multicolumn{6}{|l|}{47,5} \\
\hline$\Sigma$ & & & 33,24 & 1073,72 & \\
\hline
\end{tabular}




\subsubsection{Duração e viabilidade do ciclo total (ovo-adulto)}

A duração do período ovo-adulto, de Metallactus sp. foi de 172,99 dias, com uma viabilidade de 25,33\% (Figura 15).

A baixa viabilidade ocorreu em função do número elevado de pupas que apresentaram paralisação no desenvolvimento. Apesar de não atingirem o estágio adulto (até a data do encerramento da coleta de dados), ao serem abertas algumas escatotecas, verificoutse que as larvas maduras não estavam mortas, mas num estado de "letargia".

A duração do ciclo total foi inferior ao observado por McFayden (1987), para a espécie $M$. patogenicus em B. halimifolia, de 230 dias. 


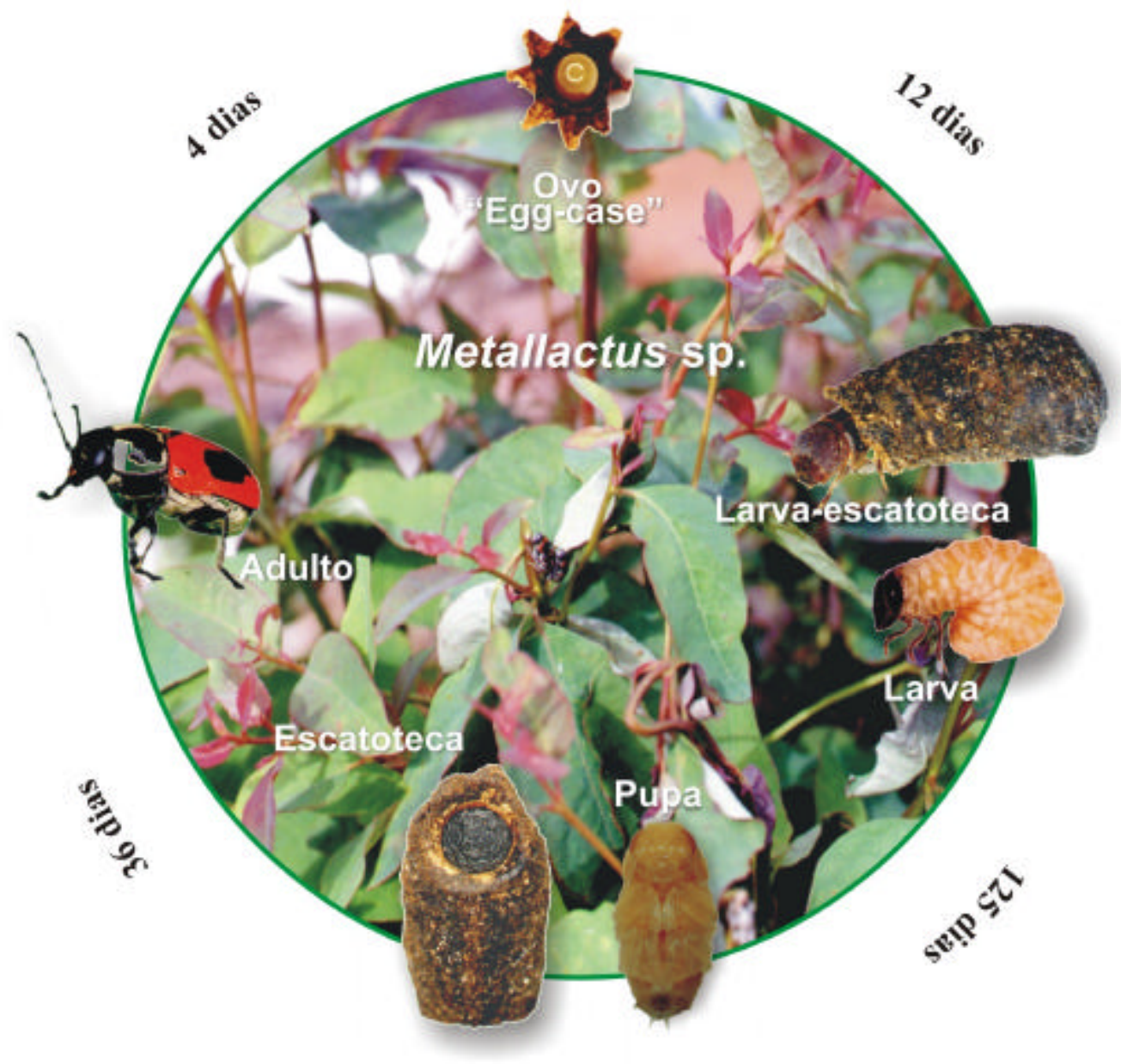

Figura 15 - Ciclo total (ovo-adulto) de Metallactus sp. em Eucalyptus urophylla. 


\subsubsection{Fase de ovo}

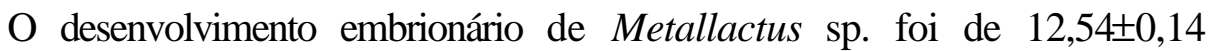
dias. A duração média obtida difere do resultado encontrado por McFayden (1985), que foi, em média, de 20 dias, com uma variação de 18 a 26 dias. A viabilidade dos ovos foi bastante elevada, sendo de $95 \pm 4,68 \%$, acredita-se que este valor tenha sido obtido, em função da não contaminação dos ovos por patógenos. Embora tenha sido observada a presença de fungo (Figura 16) na estrutura de proteção ("egg-case”), e o desenvolvimento embrionário ocorreu normalmente.

\subsubsection{Presença de microorganismos}

Observou-se a ocorrência de microorganismos (fungo) nas estruturas de proteção, "egg-case" e escatoteca; embora não comprometendo o desenvolvimento embrionário, nem a pupação. Pelo fato de não ter sido feita uma cultura do microorganismo observado, para sua identificação, nada pode ser afirmado a respeito da não interferência deste, no desenvolvimento do inseto. 


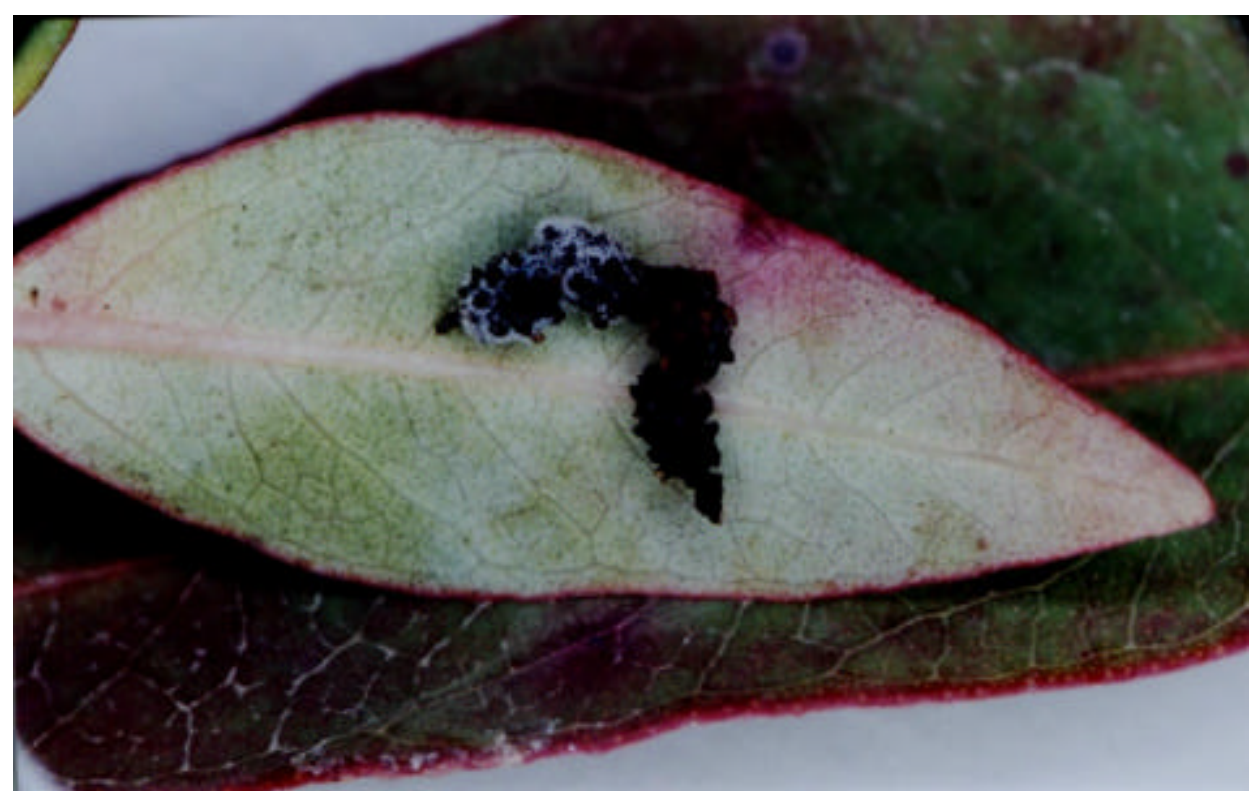

Figura 16 - "Egg-case" de Metallactus sp. com a presença de microorganismos 


\section{CONSIDERAÇÕES FINAIS}

As modificações ambientais com a introdução de monoculturas, incluindo aquelas de eucalipto, podem levar insetos herbívoros a se tornarem pragas nesses ecossistemas. Isto ocorre porque a estrutura da vegetação original determina a distribuição espacial e a disponibilidade de recursos para os herbívoros (Schowalter et al., 1986), possibilitando a ocorrência de surtos. Apesar dos danos as mudas de E. urophylla terem sido causados pelos adultos, no campo, as larvas, em laboratório, alimentaram-se de folhas de E. urophylla, o que sugere que possam adaptar-se a esse tipo de alimento, no campo, e, com isso, aumentar os danos causados a cultura do eucalipto.

Apesar dos hábitos alimentares de larvas e adultos serem distintos (Erber, 1988), esse fato não foi constatado em laboratório, utilizando-se plântulas de $E$. urophylla, como hospedeira. Então, pesquisas futuras devem concentrar-se na localização, no campo, das formas larvais e na identificação de suas fontes alimentares.

Com relação ao elevado número de pupas que apresentaram interrupção no desenvolvimento, sugere-se que seja dada continuidade à pesquisa, nesse aspecto, para verificar se pode ocorrer quiescência, (estratégia de defesa da espécie, visando a 
sobrevivência em condições ambientais adversas), para o conhecimento e planejamento de ações de controle, caso novos surtos de Metallactus sp. ocorram.

O estudo de aspectos biológicos de Metallactus sp., mantido em plântulas de E. urophylla, na fase larval, atendeu ao objetivo principal de completar o ciclo biológico na planta hospedeira, embora não tenham sido observadas, em condições naturais, larvas desse crisomelídeo e, ainda, permitiu a obtenção de uma técnica de criação que facilitará o estudo das interações inseto-planta, para o complexo coleópteros desfolhadores e eucalipto. Também viabilizará pesquisas e programas de controle biológico para este crisomelídeo, como os trabalhos de McFadyen (1987) e Schöller (1999) com parasitóides (Hymenoptera). 


\section{CONCLUSÕES}

$\Rightarrow$ A técnica de criação para o desenvolvimento larval de Metallactus sp. utilizando plântulas de Eucalyptus urophylla em papel filtro umedecido, é adequada;

$\Rightarrow$ Metallactus sp. completa o seu ciclo biológico, em plântulas de E. urophylla, em laboratório; apesar da não confirmação, em condições naturais;

$\Rightarrow$ A metodologia utilizada para medição da cápsula cefálica das larvas permitiu a definição do número de ínstares, segundo a regra de Dyar, podendo ser proposta para as espécies que possuem escatoteca. 
ANEXO 

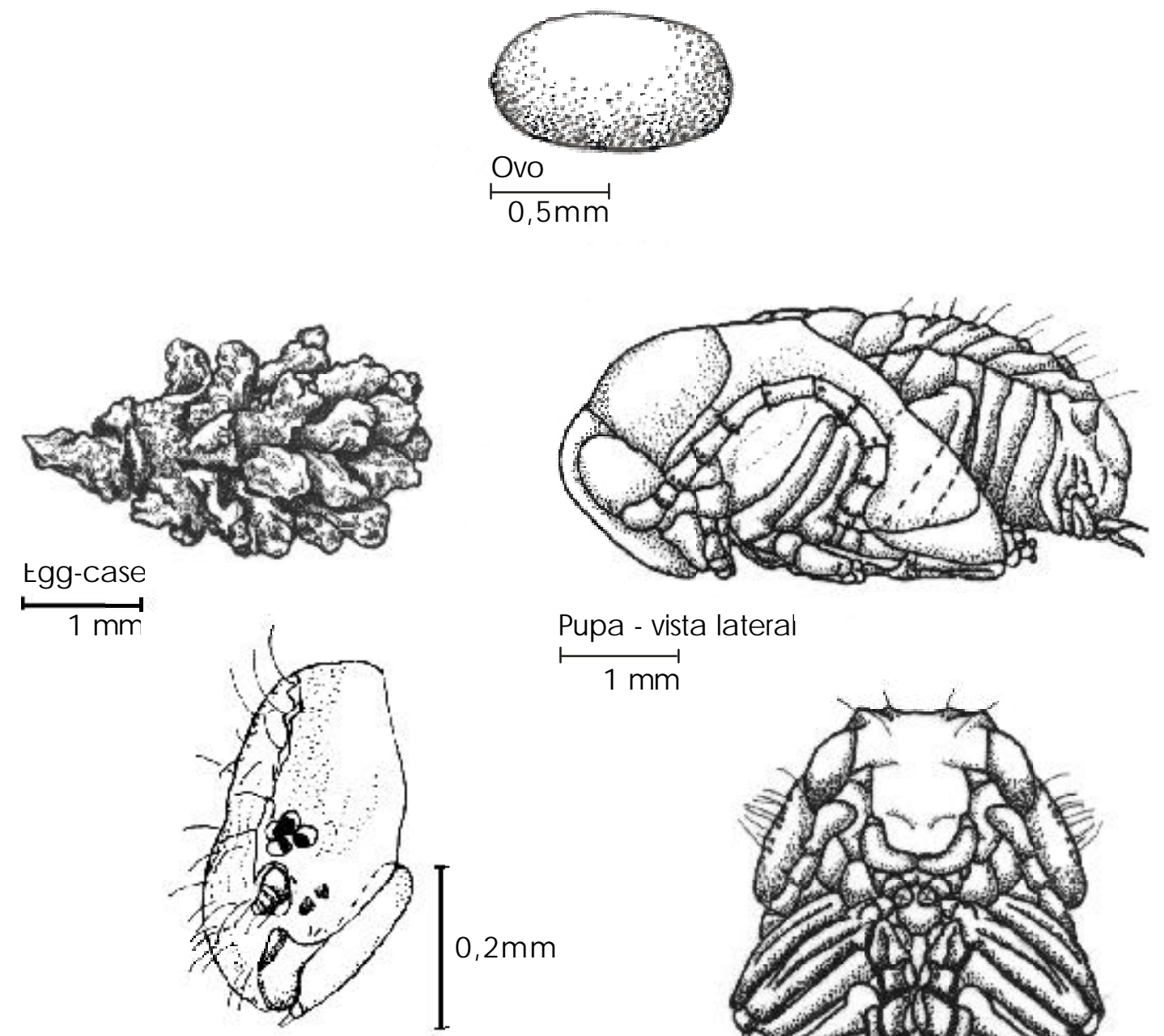

Cabe,ca-la rva 19insta r-vista la teral

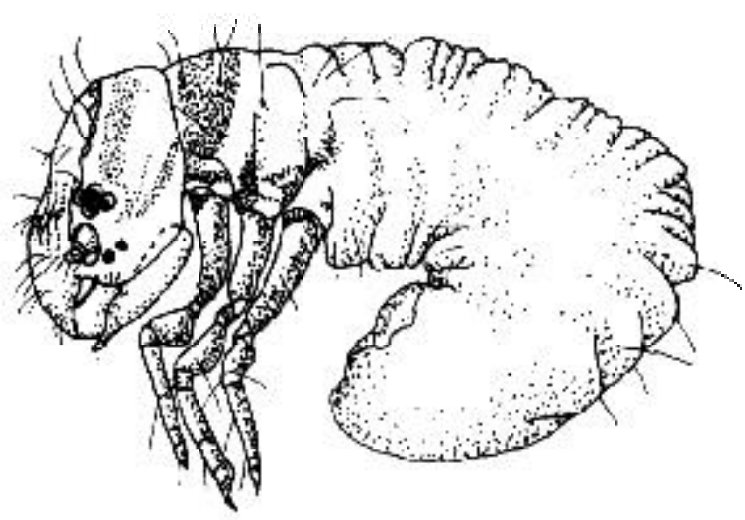

Pupa - vista laterai
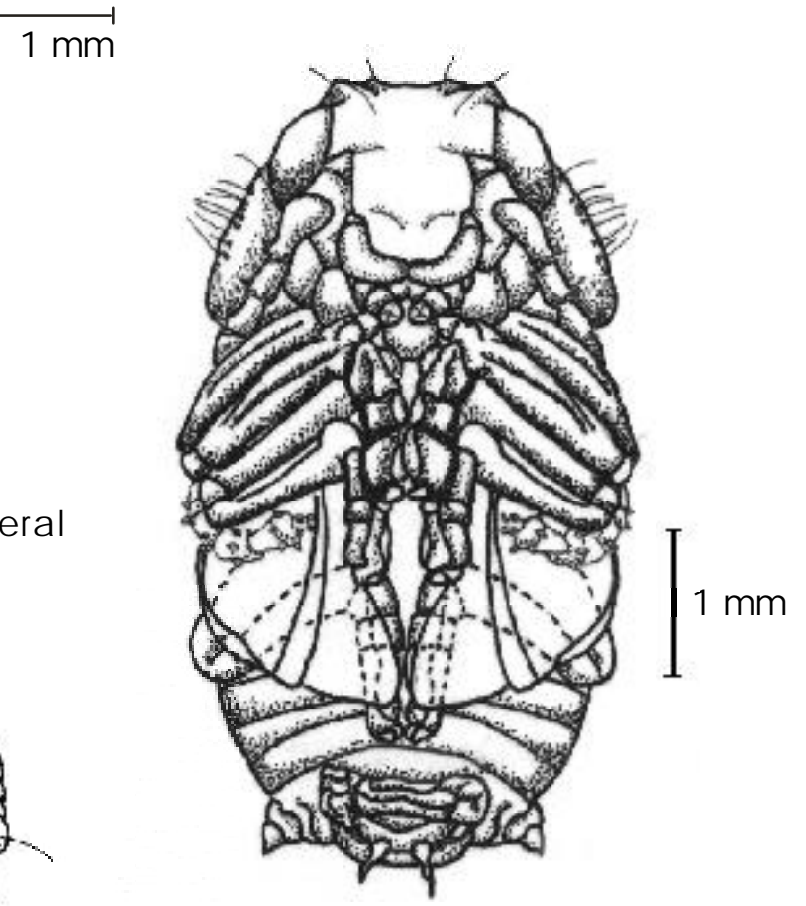

Pupa - vista ventral

Larva - ํinstar-vista la tera

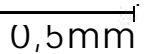

Ilustraçõesdas fases imaturas de Metallactus sp. 


\section{REFERÊNCIAS BIBLIOGRÁFICAS}

ABREU NETO, J.R.M.V. Produção de ovos de Cerotoma arcuata (Olivier) (Coleoptera: Chrysomelidae): efeito de cor do substrato e fotoperíodo. Viçosa, $1999.52 p$. Dissertação (Mestrado) - Universidade Federal de Viçosa.

ANDRADE, E.N. Uma praga do eucalypto. Chácaras e Quintais, v.37, n.5, p.463-465, 1928.

ANDRADE, E.N. O eucalipto: 2.ed. São Paulo:Cia. Brasileira de Estradas de Ferro, 1961. p.335-336. Parasitologia do eucalipto

ANJOS, N. Besouros desfolhadores de reflorestamento no Brasil. http://www.insecta.ufv.br/norivaldo/cmba/mainCMBAIngles.html (26 nov. 2002).

ÁVILA, C.J. Técnicas de criação e influência do hospedeiro e da temperatura no desenvolvimento de Diabrotica speciosa (Germar, 1824) (Coleoptera: Chrysomelidae). Piracicaba, 1999. 103p. Tese (Doutorado) - Escola Superior de Agricultura “Luiz de Queiroz”, Universidade de São Paulo.

ÁVILA, C.J.; TABAI, A.C.P.; PARRA, J.R.P. Comparação de técnicas para criação de Diabrotica speciosa (Germar) (Coleoptera: Chrysomelidae) em dietas natural e artificial. Anais da Sociedade Entomológica do Brasil, v.29, n.2, p.257-267, 2000. 
BERTI FILHO, E. Biologia de Thyrinteina arnobia (Stoll, 1782) (Lepidoptera: Geometridae) e observações sobre a ocorrência de inimigos naturais. Piracicaba, 1974. 74 p. Tese (Doutorado) - Escola Superior de Agricultura "Luiz de Queiroz", Universidade de São Paulo.

BERTI FILHO, E.; KRUGNER, T.L. Manejo integrado de pragas e doenças em povoamentos de Eucalyptus no Brasil. Silvicultura, v.41, p.41-43, 1986.

CHALFANT, R.B.; MITCHELL, E.R. Some effects of food and substrate on oviposition of the spotted cucumber beetle. Journal of Economic Entomology, v.60, p.1010-1012, 1967.

DOMINIQUE, C.R.; YULE, W.N. Laboratory rearing technique for the northern corn rootworm, Diabrotica longicornis (Coleoptera: Chrysomelidae). Canadian Entomologist, v.115, n.5, p.569-571, 1983.

ERBER, D. Biology of Comptosomata Clytrinae - Cryptocephalinae - Chlamisinae Lamprosomatinae. In: JOLIET, P.; PETITPIERRE, E.; HSIAO, T.H. (Ed.). Biology of Chrysomelidae.Dordrecht: Kluwer Academic, 1988. p.513-532.

FERNANDES, P.M. Influência da temperatura, umidade relativa do ar e dose na eficiência de Beauveria bassiana (Bals.) Vuill. sobre Cerotoma arcuata Oliv. (Col.: Chrysomelidae). Piracicaba, 1986. 68p. Dissertação (Mestrado) - Escola Superior de Agricultura “Luiz de Queiroz”, Universidade de São Paulo.

FISHER, J.R.; JACKSON, J.J.; SUTTER, G.R.; BRANSON, T.F. Influence of adult diet on damage to corn by larvae of the western corn rootworm, Diabrotica virgifera virgifera (Coleoptera: Chrysomelidae). Journal of Economic Entomology, v.79, p.114-115, 1986. 
GONZALEZ, R.; CARDONA, C.; VAN SCHOONHOVEN, A. Morfología y biología de los crisomelidos Diabrotica balteata LeConte y Cerotoma facialis Erickson como plagas del frijol comum. Turrialba, v.32, n.3, p.257-264, 1982.

HADAD, M.L.; MORAES, R.C.B.; PARRA, J.R.P. Sistema computadorizado para modeos bioestatísticos aplicados à entomologia. In: CONGRESSO BRASILEIRO DE ENTOMOLOGIA, 15., Caxambu, 1995. Resumos. Caxambu: SEB, 1995. p.244.

HAJI, F.N.P. Biologia, dano e controle do adulto de Diabrotica speciosa (Germar, 1824) (Coleoptera: Chrysomelidae) na cultura da batatinha (Solanum tuberosum L.), Piracicaba, 1981. 53p. Tese (Doutorado) - Escola Superior de Agricultura "Luiz de Queiroz", Universidade de São Paulo.

HEINECK, M.A. Ciclo vital, consumo alimentar, flutuação populacional de Cerotoma arcuata tingomariana (Bechyné, 1951) (Col., Chrysomelidae) em soja (Glycine Max (L.) Merrill). Porto Alegre, 1993. 87p. Tese (Doutorado) - Faculdade de Agronomia, Universidade Federal do Rio Grande do Sul.

HEINECK, M.A.; CORSEUIL, E. Ciclo vital e consumo alimentar de adultos de Cerotoma arcuata tingomariana Bechyné (Coleoptera: Chrysomelidae) em soja. Anais da Sociedade Entomológica do Brasil, v.34, n.3, p.579-586, 1995.

HERZOG, D.C.; EASTMAN, C.E.; NEWSOM, L.D. Laboratory rearing of the bean leaf beetle. Journal of Economic Entomology, v.67, n.6, p.794-795, 1974.

HOLCOMB, C. E.; FULTON, J.P. Rearing the bean leaf beetle, Cerotoma trifurcata, for plant virus vector studies. Plant Disease Reporter, v. 62, n.1, p. 12-14, 1978. 
JACKSON, J.J. Rearing and handling of Diabrotica virgifera and Diabrotica undecimpuctata howardi. In: KRYSAN, J.L.; MILLER,T.A. (Ed.). Methods for the study of pest Diabrotica. New York: Springer Verlag, 1986. cap.2, p.25-47.

KIRK, V.M.; CALKINS, C.O.; POST, E.J. Oviposition preferences of western corn rootworms for various soil surface conditions. Journal of Economic Entomology, v.61, n.5, p.1322-1324, 1968.

LESAGE, L. Immature stages of Canadian Neochlamisus Karren (Coleopera: Chrysomelidae). Canadian Entomologist, v.116, p.383-409, 1984.

LESAGE, L. The eggs and larvae of Pachybrachis Suffrian and P. bivittatus Say, with a key to the known immatures stages of the neartic genera of Cryptocephalinae (Coleoptera: Chrysomelidae). Canadian Entomologist, v.117, p.203-320, 1985.

LESAGE, L. The eggs and larvae of Chryptocephalus quadruplex Newman and $C$. venustus Fabricius, with a key to the known immature stages of the neartic genera of Cryptocephaline leaf beetles (Coleoptera: Chrysomelidae). Canadian Entomologist, v.118, p.97-111, 1986.

MARICONI, F.A.M. Alguns besouros de predadores de eucaliptos na região de Piracicaba. O Biológico, v.22, n.11, p. 1-14, 1956.

MARRONE, P.G.; FERRI, F.D.; MOSLEY, T.R.; MEINKE, L.J. Improvements in laboratory rearing of the southern corn rootworm, Diabrotica undecimpunctata howardi Barber (Coleoptera: Chrysomelidae), on an artificial diet and corn. Journal of Economic Entomology, v.78, p.290-293, 1985.

MASUTTI, L. Ecologia ed etologia del Cryptocephalus pini L. Bollettino di zoologia agraria bachicoltura, v.3, p.143-178, 1960. 
McFADYEN, P.J. Host-specificity and biology of Metallactus patogonicus (Col.: Chrysomelidae) introduced into Australia for the biological control of Braccharis halimifolia (Compositae). Entomophaga, v.32, n.4, p.329-331, 1987.

MEZZOMO, J.A.; ZANUNCIO, J.C.; BARCELOS, J.A.V.; GUEDES, R.N.A. Influência de faixas de vegetação nativa sobre Coleoptera em Eucalyptus cloeziana. Revista Árvore, v.22, n.1, p.77-87, 1998.

MILANEZ, J.M. Aspectos da criação de Diabrotica speciosa em condições de laboratório. In. REUNIÃO SUL BRASILEIRA DE INSETOS DE SOLO, 1., Passo Fundo, 1988 . Passo Fundo:EMBRAPA, CNPT. p.29.

MILANEZ, J.M. Técnicas de criação e biologia de Diabrotica speciosa (Germar, 1824) (Coleoptera: Chrysomelidae). Piracicaba, 1995. 102p. Tese (Doutorado) - Escola Superior de Agricultura “Luiz de Queiroz”, Universidade de São Paulo.

MILANEZ, J.M.; PARRA, J.R.P. Preferência de Diabrotica speciosa (Germar) (Coleoptera: Chrysomelidae) para oviposição em diferentes tipos e umidades de solo. Anais da Sociedade Entomológica do Brasil, v.29, n.1, p.155-158, 2000.

NAVA, D. E. Bioecologia de Cerotoma arcuatus Olivier, 1791 (Coleoptera: Chrysomelidae) e comprovação, em campo, do modelo de exigências térmicas obtido em laboratório. Piracicaba, 2000. 72p. Dissertação (Mestrado) - Escola Superior de Agricultura de Agricultura "Luiz de Queiroz", Universidade de São Paulo.

OHMART, C.P.; EDWARDS, P.B. Insect herbivory on Eucalyptus. Annual Review of Entomology, v.36, p.637-657, 1991.

OLOUMI-SADEGHI, H.; LEVINE, E. Controlling fungi that colonize eggs of the western corn rootworm in the laboratory. Entomologia Experimentalis et Applicata, v.50, p.271-279, 1989. 
PECCHIONI, M.T.D. Crianza de Diabrotica speciosa (Coleoptera: Chrysomelidae) bajo condiciones de laboratorio. Revista Peruana de Entomologia, v.31, p.86-90, 1988.

PEDROSA-MACEDO, J.H. Manual de pragas em florestas: pragas florestais do sul do Brasil. Viçosa: IPEF;SIF, 1993. 112p.

PINHEIRO, J.V. Contribuição para o conhecimento de insetos nos eucaliptais no Brasil. Anuário Brasileiro de Economia Florestal, v.14, n.14, p.245-255, 1962.

RAJNAUTH, G.L.; PEGUS; J.E.; HAQUE, S.Q. Laboratory rearing of Cerotoma arcuata (Oliv.), a beetle vector of cowpea severe mosaic virus. Tropical Agriculturist, v.64, n.3, p.191-192, 1987.

REID, C. Eucalyptus seedling herbivory by a species of Cadmus Erichson (Coleoptera: Chrysomelidae: Cryptocehalinae). Australian Journal of Entomology, v.38, p.201-203, 1999.

RIMANDO, L.C.; COREY, R.A.; SUN, Y.P. Mass rearing of the western spotted cucumber beetle. Journal of Economic Entomology, v.59, n.1, p.230-231, 1966.

SALAS, F.J.S. Criação de Cerotoma arcuata Oliv. (Coleoptera: Chrysomelidae) e transmissão de um isolado do vírus do mosaico severo do caupi. Piracicaba, 1998. 95p. Dissertação (Mestrado) - Escola Superior de Agricultura "Luiz de Queiroz", Universidade de São Paulo.

SANTOS, G.P.; VILELA, E.F.; NOGUEIRA, S.B. Estudo da bionomia e controle microbiológico de Oxydia apidania Cramer (Lepidoptera: Geometridae) desfolhador de eucalipto. Revista Árvore, v.3, n.1, p.57-74, 1979. 
SCHÖLLER, M. Field studies Cryptocephalinae biology. In: COX, M.L. (Ed.). Advances in Chrysomelidae biology. Leiden:The Netherlands: Blackhuys, 1999, p. 421-436.

SCHÖLLER, M. A new species of Metallactus Suffrian, 1866 (Coleoptera: Chrysomelidae: Cryptocephalinae) from Brazil. Russian Entomological Journal, v.12, 2003. /No prelo/.

SCHOWALTER, T.D.; HARGROVE, W.W.; CROSSLEY JR., D.A. Herbivory in forested ecosystems. Annual Review Entomology, v.31, p.177-196, 1986.

SILVA, A.G.A.; GOLÇALVES, C.R.; GALVÃO, D.M.; GONÇALVES, A.J.L.; GOMES, J.; SILVA, M.N.; SIMONI, L. Quarto catálogo dos insetos que vivem nas plantas do Brasil, seus parasitos e predadores. Rio de Janeiro: Ministério da Agricultura, 1968. 622p.

SILVA, N. A. Taxonomia, ciclo de vida e dinâmica populacional de Costalimaita ferruginea (Fabr., 1801) (Coleoptera: Chrysomelidae), praga de Eucalyptus spp. (Myrtaceae). Piracicaba, 1992. 165p. Tese (Doutorado) - Escola Superior de Agricultura “Luiz de Queiroz”, Universidade de São Paulo.

SILVA-WERNECK, J.O.; DE FARIA, M.R.; ABREU-NETO, J.R.M.V.; MAGALHÃES, B.P.; SCHMIDT, F.G.V. Técnicas de criação de Diabrotica speciosa (Germ.) (Coleoptera: Chrysomelidae) para bioensaios com bacilos e fungos entomopatogênicos. Anais da Sociedade Entomológica do Brasil, v.24, n.1, p.45-52, 1995.

SILVEIRA NETO, S.; NAKANO, O; BARBIN, D.; VILLA NOVA, N.A. Manual de ecologia dos insetos. São Paulo: Ceres, 1976.419p. 
SKELTON, T.E.; HUNTER, P.E. Laboratory rearing and reproduction of the spotted cucumber beetle. Journal of Economic Entomology, v.63, n.3, p.948-950, 1970.

SOCIEDADE BRASILEIRA DE SILVICULTURA. Área reflorestada com espécies de eucalipto em alguns Estados do Brasil. http://www.sbs.org.br (04 nov. 2002).

SUTTER, G.R.; KRYSAN, J.L.; GUSS, P.L. Rearing the southern corn rootworm on artificial diet. Journal of Economic Entomology, v. 64, n.1, p. 65-67, 1971.

WHITE, G. Metallactus sp. near nigrofasciatus for biocontrol of groundsel bush Baccharis halimifolia. News Bulletin Entomological Society Queensland, v.3, n.5, p.88, 1975.

ZANUNCIO, J.C.; LIMA, J.O.G. Ocorrência de Sarsina violascens (Lepidoptera: Lymantriidae) em eucaliptos em Minas Gerais. Brasil Florestal, v.6, n.3, p.48-50, 1975.

ZANUNCIO, J.C.; BRAGANÇA, M.A.L.; LARANJEIRO, A.J.; FAGUNDES, M. Coleópteros associados à eucaliptocultura nas regiões de São Mateus e Aracruz, Espírito Santo. Revista Ceres, v.41, n.232, p.584-590, 1993.

ZANUNCIO, J.C.; FAGUNDES, M.; ANJOS, N.; ZANUNCIO, T.V.; CAPITANI, L.R. Levantamento e flutuação populacional de lepidópteros associados à eucaliptocultura: V- Região de Belo Oriente, Minas Gerais. Revista Árvore, v.14, n.1, p.35-44, 1990. 